This article can be cited before page numbers have been issued, to do this please use: M. J. Riveira, L. A. Marsili and M. P. Mischne, Org. Biomol. Chem., 2017, DOI: 10.1039/C7OB02220D.

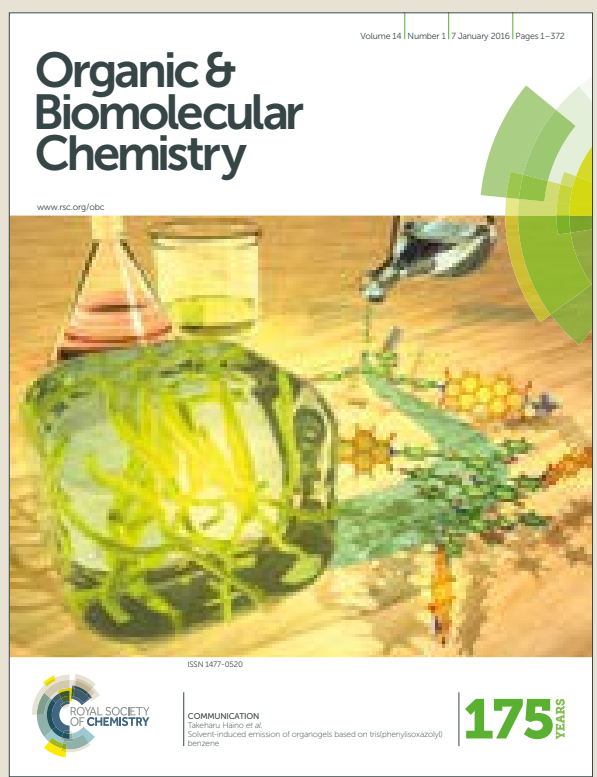

This is an Accepted Manuscript, which has been through the Royal Society of Chemistry peer review process and has been accepted for publication.

Accepted Manuscripts are published online shortly after acceptance, before technical editing, formatting and proof reading. Using this free service, authors can make their results available to the community, in citable form, before we publish the edited article. We will replace this Accepted Manuscript with the edited and formatted Advance Article as soon as it is available.

You can find more information about Accepted Manuscripts in the author guidelines.

Please note that technical editing may introduce minor changes to the text and/or graphics, which may alter content. The journal's standard Terms \& Conditions and the ethical guidelines, outlined in our author and reviewer resource centre, still apply. In no event shall the Royal Society of Chemistry be held responsible for any errors or omissions in this Accepted Manuscript or any consequences arising from the use of any information it contains. 


\section{The Iso-Nazarov Reaction}

Martín J. Riveira, ${ }^{*}$ Lucía A. Marsili and Mirta P. Mischne*

Departamento de Química Orgánica

Instituto de Química Rosario (CONICET_UNR), Facultad de Ciencias Bioquímicas y Farmacéuticas,

Universidad Nacional de Rosario

Suipacha 531, 2000 - Rosario, Argentina

E-mail: riveira@iquir-conicet.gov.ar, mischne@iquir-conicet.gov.ar

\section{TABLE OF CONTENTS ENTRY}

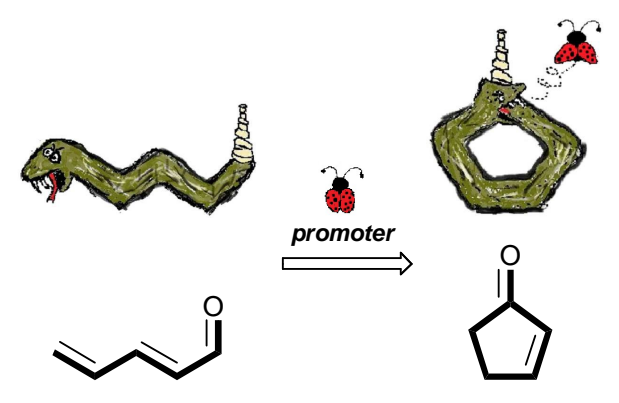

The acid-promoted cycloisomerization of conjugated dienals and linearly-conjugated dienones for the synthesis of five-membered ring systems is reviewed. 


\title{
The Iso-Nazarov Reaction
}

\author{
Martín J. Riveira, ${ }^{*}$ Lucía A. Marsili and Mirta P. Mischne* \\ Departamento de Química Orgánica \\ Instituto de Química Rosario (CONICET_UNR), Facultad de Ciencias Bioquímicas y Farmacéuticas, \\ Universidad Nacional de Rosario \\ Suipacha 531, 2000 - Rosario, Argentina \\ E-mail: riveira@iquir-conicet.gov.ar, mischne@iquir-conicet.gov.ar
}

Mirta P. Mischne obtained her Ph. D. at Universidad Nacional de Rosario (UNR), Argentina, in 1986. After post-doctoral studies under the supervision of Prof. Andrew E. Greene in Grenoble, France, she returned to the UNR, where she is currently Professor at Facultad de

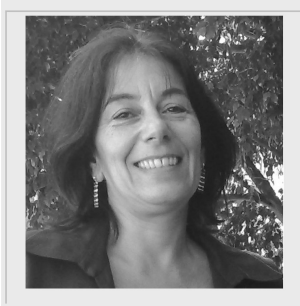

Ciencias Bioquímicas y Farmacéuticas (IQUIR-CONICETUNR). Her research interests focus on the development of new domino reactions based on the chemistry of polyunsaturated carbonyl compounds including photooxygenation and cycloisomerization processes.

Martín J. Riveira graduated with a Bachelor's degree in Chemistry in 2009 from Universidad Nacional de Rosario (UNR) and then worked on the development of domino reactions of polyunsaturated carbonyl compounds under the supervision of Prof. Mirta P. Mischne. After earning his Ph. D. degree in 2014, he joined the group of Prof. Ernesto G. Mata as a postdoctoral fellow working on the application of transitionmetal-catalyzed reactions to solid-phase organic synthesis. In 2017 he was appointed assistant researcher at CONICET. His research interests gravitate towards the development of new domino reactions based on cycloisomerizations.

Lucía A. Marsili is an undergraduate student at Facultad de Ciencias Bioquímicas y Farmacéuticas (Universidad Nacional de Rosario). While pursuing her Bachelor's degree in Chemistry, she is now involved in the development of novel variants of the Iso-Nazarov reaction.
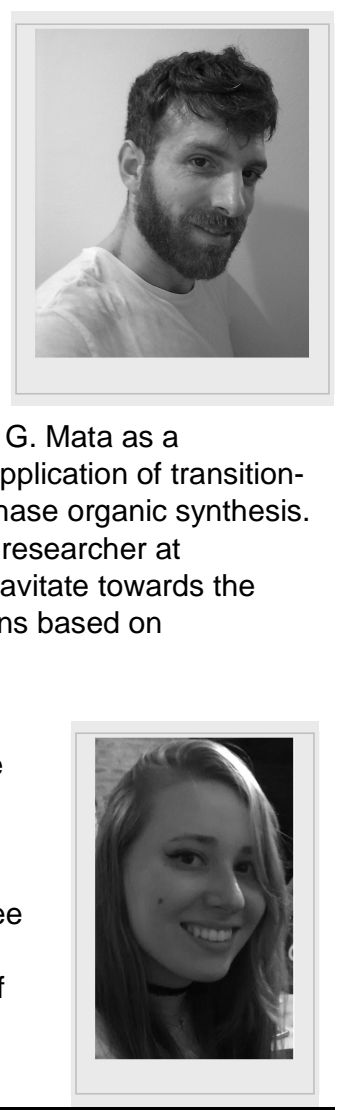
Abstract: The construction of five-membered rings is essential in organic chemistry. In this context, pentannulation reactions that provide a straightforward access to cyclopentenones are of particular interest, as these structures are not only embedded in important molecules such as some prostaglandins, but also serve as versatile building blocks in organic synthesis. This review documents on the acid-promoted cycloisomerization of conjugated dienals and linearly-conjugated dienones for the construction of cyclopentenones, a transformation that has been largely eclipsed by the well-known Nazarov reaction, i. e. the acid-promoted cycloisomerization of cross-conjugated ketones.

\section{Introduction}

Cycloisomerization reactions are undoubtedly attractive atom-economical transformations in synthetic planning. ${ }^{1}$ The proper combination of an activator and a suitable polyunsaturated precursor just triggers the fine dancing of atoms and electrons that allows the efficient preparation of complex cyclic and polycyclic frameworks. Naturally, nothing is wasted in these processes and, in some cases, high levels of stereo- and regioselectivity can be attained. In particular, since the pioneering works of I. Nazarov, the cycloisomerization reaction that carries his name has evolved into a well-established methodology for cyclopentannulation. ${ }^{2,3}$ Basically, the classic version of this essential reaction involves the initial activation, either by a Brønsted or a Lewis acid, of a cross-conjugated dienone (1, Scheme $1 \mathrm{~A})$. The pentadienyl cation thus formed (2), then undergoes a $4 \pi e^{-}$electrocyclic ring-closure to provide a brand new oxyallyl cation (cyclopentenyl cation 3 ) that after elimination affords the corresponding conjugated cyclopentenone product (4).

A) Nazarov reaction

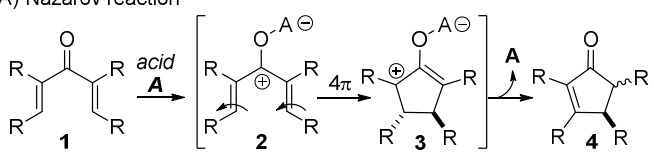

B) Iso-Nazarov reaction

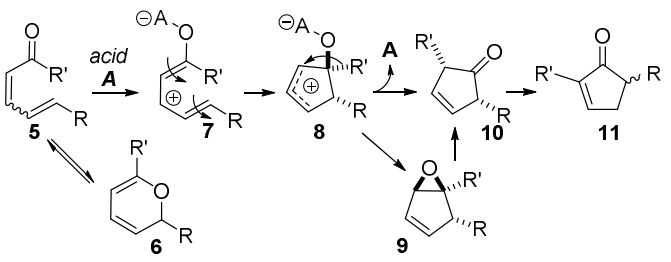

Scheme 1. Acid-promoted isomerization of cross- and linearly-conjugated unsaturated carbonyl compounds.

Cyclopentenones are unarguably distinguished structural motifs, not only versatile as synthetic intermediates, ${ }^{4}$ but also present in notable natural molecules such as some aflatoxins, prostaglandins, jasmone and phorbol, just to name a few. ${ }^{5}$ This importance probably triggered, especially these last decades, continuous efforts on the understanding of the Nazarov reaction by several groups, taking the process to a mature state and rendering this reaction one of the most valuable tools for cyclopentenone construction. Some accomplishments in the field include the application to the total synthesis of natural products, ${ }^{6}$ the development of regio- and stereoselective versions, ${ }^{7}$ the design of cascade reactions involving the Nazarov cyclization ${ }^{8}$ and the extension of the reaction to other substrates capable of providing the key pentadienyl cation intermediates. $^{9}$ 
Some alternative substrates for the $4 \pi e^{-}$-conrotatory electrocyclization comprise $\alpha, \beta, \gamma, \delta$-unsaturated carbonyl compounds such as dienals and dienyl-ketones (5, Scheme 1B). The development of this type of transformation, originally baptized as the anomalous Nazarov reaction by Denmark ${ }^{10}$ and then as the isoNazarov reaction by Trauner, ${ }^{11}$ has been clearly eclipsed by the high popularity of the traditional Nazarov reaction using divinyl ketones. It is the purpose of the present review to document on the state of the art of the hereinafter iso-Nazarov reaction. Presented below is an overview of the literature precedents since its beginning, including our own contributions to the field. These have been organized in five sections and, for the sake of clarity, most sections will be disclosed in chronological order. It should be noted that analogous radical $^{12}$ and transition-metal-mediated ${ }^{13}$ versions of this cycloisomerization have been developed, but these are outside the scope of the present review.

\section{Iso-Nazarov Reactions}

Along the way to cyclopentenones, an inspection of Scheme 1 reveals there are three main differences when linearly conjugated carbonyl compounds are used as substrates instead of divinyl ketones. First, an interesting feature in the iso-Nazarov pathway is that for cyclopentenones to form, a group migration is required. That is, after $4 \pi$ electrocyclization, migration of group R' in $\mathbf{8}$ allows for the formation of the carbonyl group. Particularly in the case of dienones, the capability of different alkyl or aryl R' groups to migrate will determine the possibility of forming cyclopentenone products. Secondly, unlike divinyl-ketones, dienals and linearly-conjugated dienones (5) are in equilibrium with their $2 H$-pyran valence-isomers 6 through an oxa- $6 \pi$ electrocyclic reaction. ${ }^{14}$ Whereas in some cases this equilibrium does not limit the pool of substrates available for the iso-Nazarov process, in some others it can also be completely shifted toward reactive pyran isomers that can be trapped in subsequent transformations. For instance, dienal 12 is a putative intermediate in Hayashi's biomimetic synthesis of the angiogenesis inhibitor (+)-epoxyquinol A (14) (Scheme 2). ${ }^{15}$ Compound 12, obtained via $\mathrm{MnO}_{2}$ allylic oxidation of the corresponding alcohol, undergoes an oxa-6 $\pi$-electrocyclic ring closure towards $2 \mathrm{H}$-pyran 13 which readily dimerizes via a Diels-Alder-type [4+2] cycloaddition to afford the natural product 14. Finally, the iso-Nazarov reaction can provide, depending upon the conditions, the thermodynamically less stable 3-cyclopentenones as products (10) and not necessarily the conjugated ones commonly obtained by the traditional Nazarov cyclization.

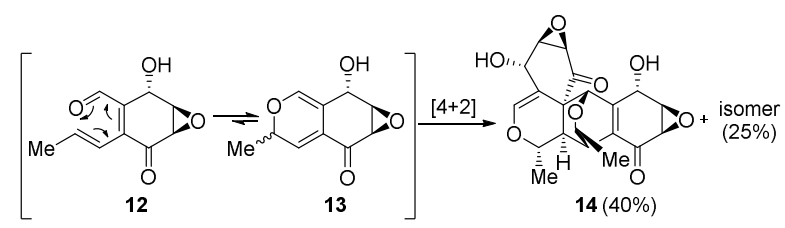

Scheme 2. Equilibrium shift in the dienal/2H-pyran valence isomerism.

As regards the mechanism of the iso-Nazarov reaction, it should be noted that a non-pericyclic ionic pathway can as well be proposed involving an intramolecular Prins reaction. de Lera and co-workers performed computational studies on this as well as other reactions involving hydroxy-pentadienyl cations as intermediates, e.g. the Nazarov reaction and the Piancatelli rearrangement. ${ }^{16}$ His results are in accord with the pericyclic pathway involving the conrotatory electrocyclic ring closure. Notwithstanding this, as shall be seen 
below, several authors have evoked this alternative ionic mechanism to account for certain experimental observations.

Surprisingly, to our knowledge, the first examples on the cycloisomerization of linearly conjugated dienecarbonyl compounds did not involve dienones or dienals but dienoic acid chlorides. In 1962 Märkl et al. showed that Lewis acid $\mathrm{AlCl}_{3}$ promoted the isomerization of acid chloride $\mathbf{1 5}$ at room temperature to afford the 2-cyclopentenone product 17 in good yield (Scheme 3). ${ }^{17}$ Many years later, in 1979, the same cyclopentenone product 17 was also obtained by $\mathrm{AlCl}_{3}$ treatment of the isomeric dienoyl chloride $16 .{ }^{18}$

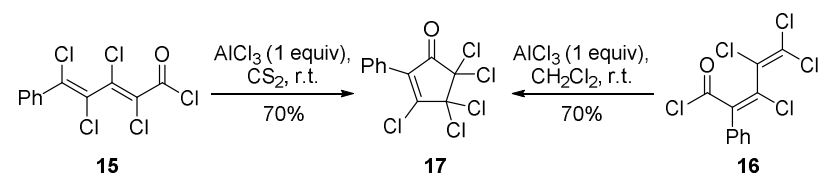

Scheme 3. First examples on the cycloisomerization of dienylcarbonyl compounds.

The same year, the group of Ogawa reported the isomerization of conjugated all-trans-dienals 18 using concentrated hydrochloric acid in THF at $40{ }^{\circ} \mathrm{C}$ (Sch eme 4). ${ }^{19}$ Consistent with the mechanism depicted in Scheme $1 \mathrm{~B}$, the authors stated that non-conjugated cyclopentenones 19 were the initially obtained products of these cycloisomerizations. Instead, if temperature was raised above $45^{\circ} \mathrm{C}$, a ca. 1:1 mixture of isomerized 2cyclopentenones $\mathbf{2 0}$ and $\mathbf{2 1}$ was obtained. Unfortunately, no information about yields, stereoselectivity or the amount of acid used is provided in the manuscript and the ${ }^{1} \mathrm{H}$ NMR data of only one product is reported. Shortly after, the cyclization of 2-methyl-2,4-hexadienal to 2,5-dimethyl-2-cyclopentenone in hot $5 \%$ oxalic acid solution was reported as an unwanted side-reaction by the group of Heck. ${ }^{20}$

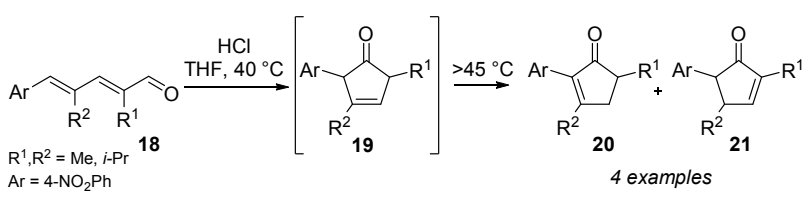

Scheme 4. First examples on the cycloisomerization of dienals.

In the course of their studies on silicon-directed Nazarov reactions, ${ }^{21}$ Hite and Denmark reported an anomalous cyclization of dienyl vinyl ketones (Scheme $5 \mathrm{~A}$ ). ${ }^{10}$ As shown, the cyclization of substrate 22a using iron chloride as promoter in dichloromethane at room temperature provided non-conjugated cyclopentenone 23a in $44 \%$ yield. Although this transformation could be explained by a classic Nazarov pathway followed by cationic migrations (Scheme 5B), this mechanism could not account neither for the formation of 24a at lower temperatures, nor the outcome of ${ }^{13} \mathrm{C}$-isotopic labeling studies (see Schemes $5 \mathrm{~A}$ and $5 \mathrm{C}$ ). In this manner, the authors introduced the mechanism of the iso-Nazarov reaction involving hydroxy-pentadienyl cation $\mathbf{D}$ that, after cyclization and 1,2-group migration provides the same product $24 \mathbf{b}$ (i.e. ${ }^{13} \mathrm{C}$-labeled 24a). Scheme 5D exhibits other dienyl vinyl ketones that also underwent this iso-Nazarov cyclization. In particular, styryl-sidechain bearing substrate $\mathbf{2 2} \mathbf{g}$ provided a mixture of both cyclopentenone products $\mathbf{2 4} \mathbf{g}$ and protodesilylated $\mathbf{2 3} \mathbf{g}$ (ratio $0.77: 1,78 \%$ combined yield). Surprisingly, other substrates lacking the cross-conjugated motif (for example substrates 22 with $\mathrm{R}^{2}=\mathrm{Me}, t-\mathrm{Bu}, \mathrm{Ph}$ ) did not undergo the discovered process. Since $\mathrm{R}^{2}$ is the group that migrates, this failure was unsettling as for instance phenyl groups are well-known to participate in pinacol 
rearrangements. In addition, the transformation proved to be stereospecific: the use of pure $(E, E)$-22 $\mathbf{g}$ provided the corresponding products $\mathbf{2 3}$ and $\mathbf{2 4}$ as single diastereoisomers (trans). On the other hand, the use of a

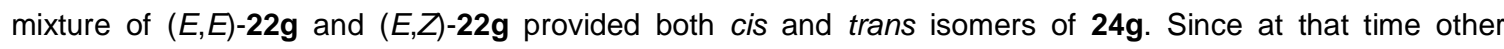
authors had already dealt with "normal" Nazarov reactions of dienyl vinyl ketones, ${ }^{22}$ the success of the devised iso-Nazarov pathway was attributed to the Z-geometry of the $\alpha, \beta$-unsaturation of the reacting dienone moiety.

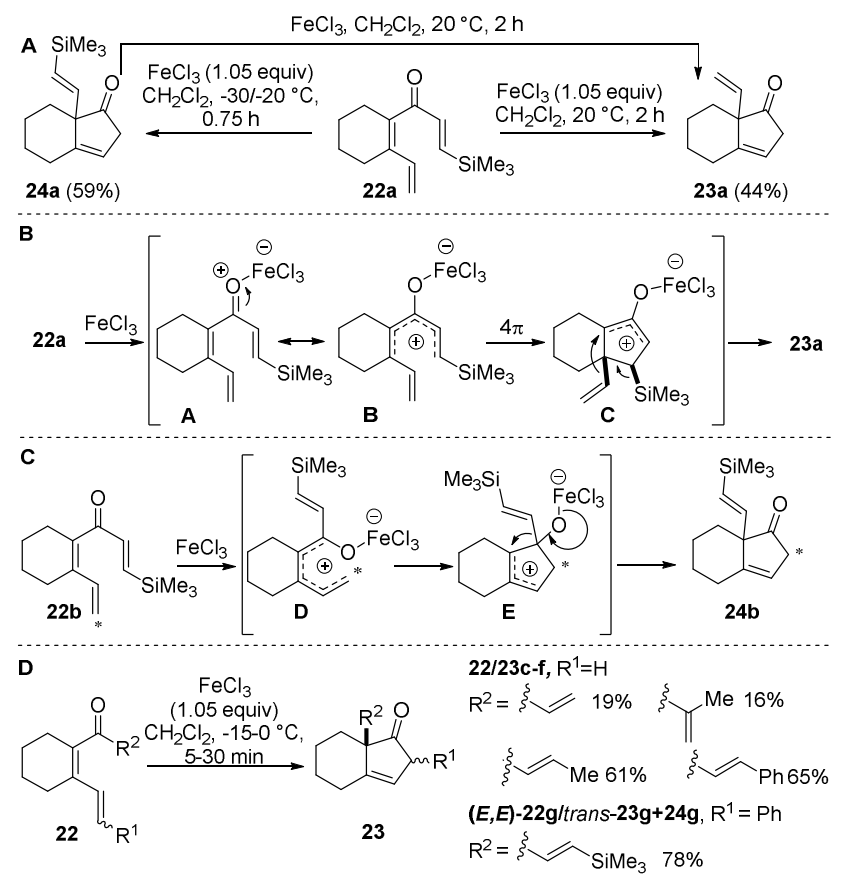

Scheme 5. First examples of the iso-Nazarov cyclization of dienyl vinyl ketones.

The isomerization of aldehyde 2,4-hexadienal (25) to 2-methyl-2-cyclopentenone (26) in $\mathrm{FSO}_{3} \mathrm{H} / \mathrm{CD}_{2} \mathrm{Cl}_{2}$ was reported by Elia et al. in 1991 (Scheme 6). ${ }^{23}$ Protonated $25(\mathbf{A})$, initially formed at $-78{ }^{\circ} \mathrm{C}$, was shown to be stable for several hours at $-60^{\circ} \mathrm{C}$ and could also be characterized by ${ }^{1} \mathrm{H}$ and ${ }^{13} \mathrm{C}$ NMR. When temperature was increased above $30^{\circ} \mathrm{C}$, however, A cycloisomerized into cation $\mathbf{H}$, i. e. protonated 26. Cyclopentenone $\mathbf{2 6}$ could be retrieved by neutralization of $\mathbf{H}$ and its identification was confirmed via an independent synthesis. Due to the large negative entropy of activation measured for the isomerization of $\mathbf{A}$ to $\mathbf{H}$, a dication was proposed as intermediate $(\mathbf{B})$. On the other hand, the key role of intermediate $\mathbf{D}$, which could also be characterized by NMR, was also established. Irradiation of A in a quartz Dewar $\left(\lambda_{\max }=338 \mathrm{~nm}\right)$ provided a 7:3 mixture of $\mathbf{A}$ and $\mathbf{D}$ that already underwent isomerization to $\mathbf{G}$ at $-40{ }^{\circ} \mathrm{C}$. Upon heating to $-10{ }^{\circ} \mathrm{C}$ this cation, also identified by NMR, was found to further rearrange to $\mathbf{H}$. No yield for the production of $\mathbf{2 6}$ was reported.

In 2000, Kuroda and Koshio reported the cycloisomerization of dienals 27a-c bearing a trimethylsilylmethyl group at the $\alpha$ carbon (Scheme 7). ${ }^{24}$ The reaction was promoted by anhydrous $\mathrm{FeCl}_{3}(2$ equiv) and provided the spirocyclic products 28a-c in good yields. Other Lewis acids such as $\mathrm{BF}_{3} . \mathrm{OEt}_{2}, \mathrm{AlCl}_{3}$ and $\mathrm{Et}_{2} \mathrm{AICl}$ were also tested but without success. In particular, for substrates $27 \mathbf{b}$-c , the reaction was found to proceed stereoselectively, affording the corresponding cyclopentenones as single diastereoisomers. This was 
rationalized by a preferential equatorial attack of the $\gamma, \delta$-double bond. Although a complete mechanistic scenario was not provided, cycloalkenol 29 was proposed as key intermediate of the reaction (see Scheme 1B, protonated 8). The authors found that the silyl group may play an important role in stabilizing cationic intermediates of the reaction since analogous substrate $\mathbf{2 7 d}$ did not participate in the cyclization.

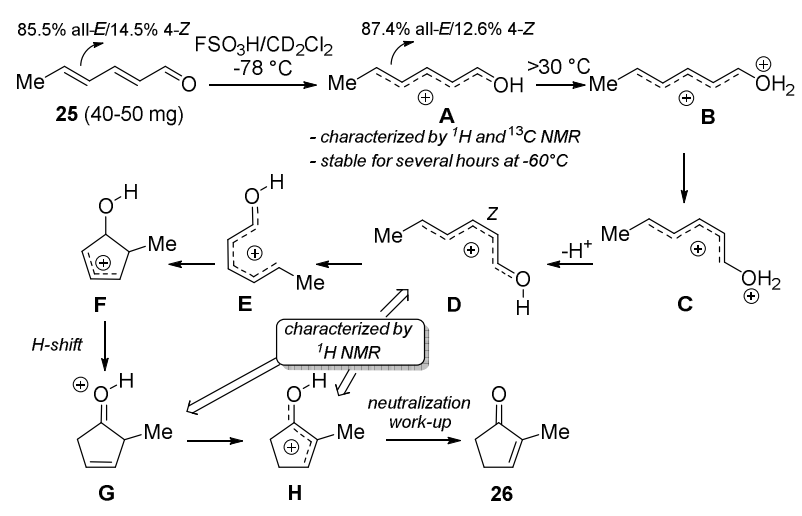

Scheme 6. NMR studies on the isomerization of 2,4-hexadienal in $\mathrm{FSO}_{3} \mathrm{H}$.

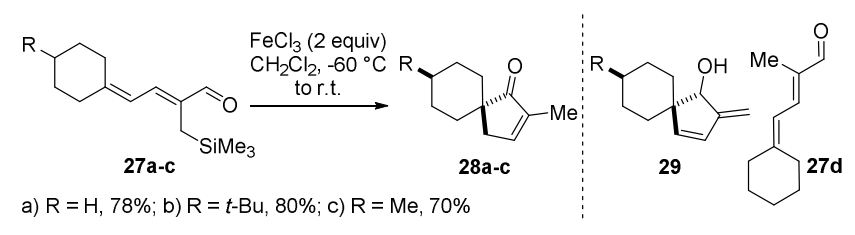

Scheme 7. Isomerization of 2-(trimethylsilylmethyl)-pentadienals for the synthesis of spirocyclic cyclopentenones.

In 2003, Trauner's group introduced the Lewis-acid catalyzed cycloisomerization of (2Z)-dienals that they named the iso-Nazarov cyclization (Scheme 8A). ${ }^{11}$ 2-Cyclopentenones 31a-d were obtained as single regioisomers using a catalytic amount of $\mathrm{Me}_{2} \mathrm{AICl}$ as Lewis acid. Indeed, one of these cyclopentenones (31a) had been prepared by Ogawa and co-workers using concentrated $\mathrm{HCl}$ and an all-trans-dienal (20, Scheme 4). Interestingly, product 31b was found to be accompanied by side-product 32, the formation of which can be explained by an interrupted iso-Nazarov reaction involving the trapping of a cyclopentenyl cation intermediate (such as 8 ) by the catalyst (Scheme 8B). The pattern of substituents in the dienal substrates seemed to play a major role as extended cinnamaldehyde $\mathbf{3 3}$ only underwent $E$ - $Z$ isomerization under the reaction conditions employed for the isomerization. Apart from the iso-Nazarov pathway involving the conrotatory $4 \pi$ electrocyclization, the authors proposed yet another mechanism involving a pericyclic $\left[{ }_{\pi} 4 \mathrm{a}+{ }_{\pi} 2_{\mathrm{a}}\right]$ cycloaddition (Scheme $8 \mathrm{C}$ ). The epoxide thus formed would then isomerize in the presence of acid to the obtained cyclopentenone product.

As an application of their studies on pentadienylations of aldehydes using 4-ethoxy-1,2-bis(sulfenyl)buta-1,3-dienes, the same year, Yoshimatsu and co-workers reported the cyclization of aldehydes 38a and 38b (Scheme 9). ${ }^{25}$ The only two substrates tested were found to be quite reactive, probably due to the presence of the cation-stabilizing heteroatoms, and the cyclizations only took 30 minutes using $p$-TSA (0.1 
equiv) as additive at room temperature. The carbonyl-ene type mechanism was proposed to account for the formation of cyclopentenone products 39. It should be noted that the stereochemistry of the starting materials could not be unambiguously determined by NOE experiments and it was only established by comparison with other dienals prepared.

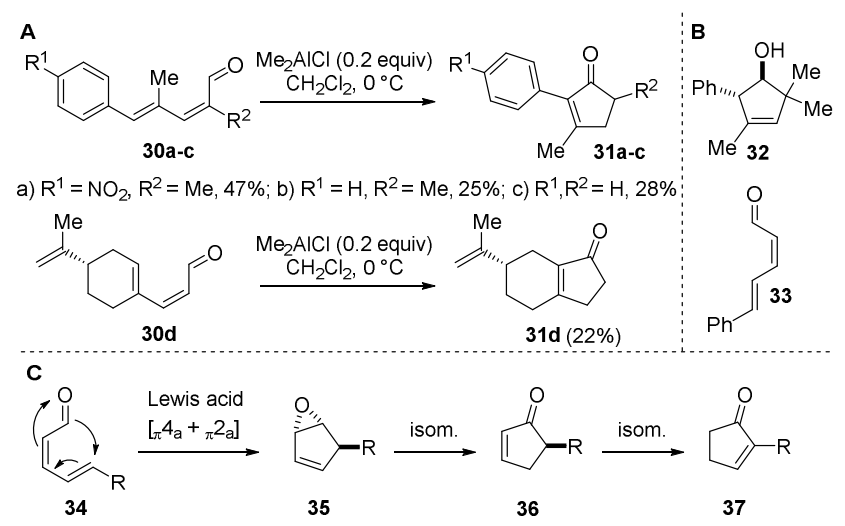

Scheme 8. Catalytic iso-Nazarov cyclization of $(2 Z, 4 E)$-dienals.

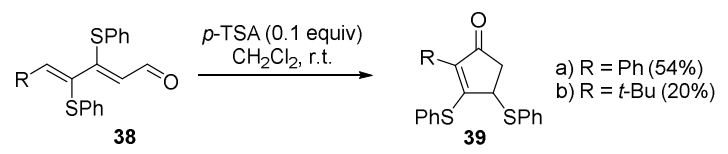

Scheme 9. Catalytic iso-Nazarov cyclization of $(2 Z, 4 Z)$-dienals.

A few years later after their first report, Kuroda and collaborators reported an extension of their work in order to gain more insight into the iso-Nazarov reaction (Scheme 10). ${ }^{26}$ By evaluating isomers of the original starting materials $\mathbf{2 7}$ and other reaction conditions, a complete picture of the mechanism was gathered. When substrate $(2 E)$-27a was treated with $\mathrm{FeCl}_{3}$ at $0^{\circ} \mathrm{C}$, cyclopentenone 40 a was obtained within only 20 min in $41 \%$ yield. A two fold increase in yield was obtained when 10 equiv. of the acid were added (Scheme 10A). If temperature was kept at $-60{ }^{\circ} \mathrm{C}$, originally expected cyclopentenol $29 \mathrm{a}$ was the product of the cycloisomerization. The previously obtained conjugated 2-cyclopentenone 28a was produced as a result of a slow isomerization process of $40 \mathrm{a}$ at $-60^{\circ} \mathrm{C}$. The diastereoisomers of substrates $27 \mathrm{~b}$ and $27 \mathrm{c}$ (Scheme 7) were also evaluated with similar results except for the fact that cyclopentenol isomers were either not isolated or found to be unstable. Other 2-trimethylsilylmethyl-dienals were evaluated as well. In an attempt to oxidize allylic alcohols 41a-c to the corresponding dienals using $\mathrm{MnO}_{2}$, it was found that the reaction conditions already promoted the iso-Nazarov rearrangement to deliver the cyclopentenols $42 a-c$ in good yields. Since the dienols 42a-c were originally obtained as mixtures with their corresponding trimethylsilyl ethers, the crude reaction mixtures were treated with $n$ - $\mathrm{Bu}_{4} \mathrm{NF}$. The cyclization was found to be stereoselective featuring a cisrelationship between the hydroxyl group and the $\alpha$-hydrogen. Notwithstanding this, the incorporation of a substituent in the cyclohexane ring in $\mathbf{4 1} \mathbf{b}, \mathbf{c}$ did not impair any effect and products $\mathbf{4 2} \mathbf{b}, \mathbf{c}$ were isolated as 1:1 mixtures of diastereoisomers. Along with the finding of cyclopentenol $\mathbf{3 2}$ by Trauner's group, these represent the first examples of cascade processes based on the iso-Nazarov reaction (see next section). Dienal $\mathbf{4 3}$ could 
indeed be obtained via oxidation of the corresponding alcohol but behaved differently than the putative diastereoisomeric dienal. Upon treatment with $\mathrm{FeCl}_{3}$, a complex mixture of at least seven compounds, including oxidation products, was obtained. Among these, conjugated cyclopentenone $\mathbf{4 4}$ was found as the major product and could be isolated in ca. $36 \%$ yield.

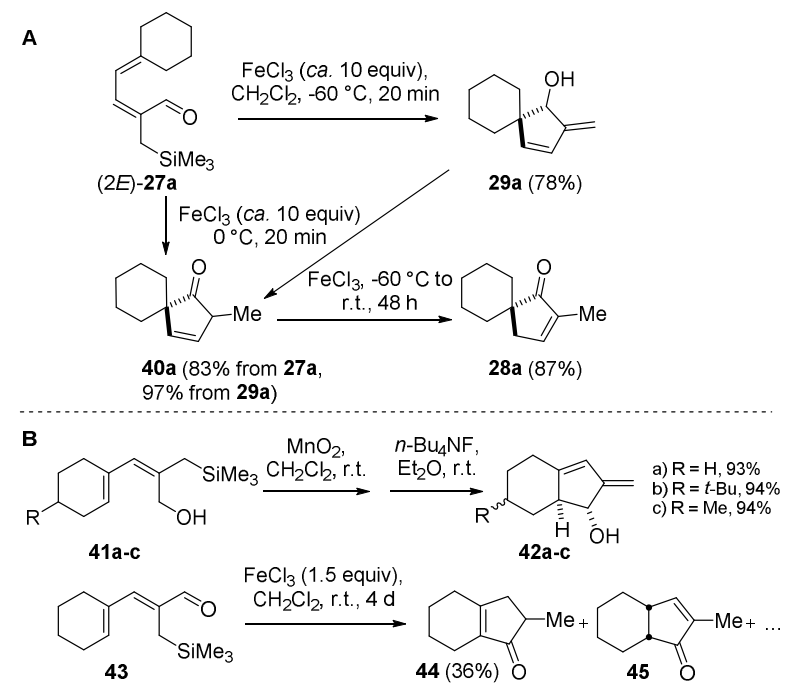

Scheme 10. Iso-Nazarov cyclization of 2-(trimethylsilylmethyl)-pentadienals.

In an attempt to oxidize propargylic alcohol 46 under Parikh-Doering conditions, Porter and coworkers obtained an unexpected conjugate addition product (47, Scheme 11$).{ }^{27}$ This dienal $\mathbf{4 7}$, obtained as a 10:1 mixture of $E: Z$ isomers, underwent a smooth iso-Nazarov cyclization when dissolved in $\mathrm{CDCl}_{3}$. The facile cycloisomerization was attributed to the assistance of the $\gamma$-nitrogen atom and to the presence of traces of acid in the deuterated solvent. A Nazarov pathway as well as a carbonyl-ene type mechanism were proposed to account for the spontaneous transformation which led to a single regioisomer of $\mathbf{4 8}$. No yield was reported for the iso-Nazarov step.

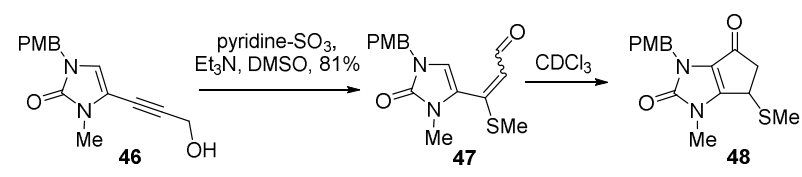

Scheme 11. Iso-Nazarov cyclization of a dienal in $\mathrm{CDCl}_{3}$.

In 2006 the group of Liu reported the iso-Nazarov cyclization of both monocyclic and acyclic cis-2,4dienals 49 (Scheme 12). ${ }^{28}$ The process was catalyzed by $\mathrm{PtCl}_{2}(5 \mathrm{~mol} \%)$, leading to the corresponding 3cyclopentenones $(\mathbf{5 0})$ in high yields. Since some substrates bearing a bulky substituent at the $\alpha$-carbon $(t$-Bu or $\mathrm{Ph}$ ) underwent skeletal rearrangement (Scheme $12 \mathrm{~B}$ ), an alternative mechanism to that involving the $4 \pi \mathrm{e}^{-}$ electrocyclization was proposed. This proposal features an initial carbonyl-ene type reaction and a bicyclic epoxide as intermediate (B). In addition, both ${ }^{2} \mathrm{H}$ - and ${ }^{13} \mathrm{C}$-labeling studies were performed in order to validate the mechanistic proposal. 


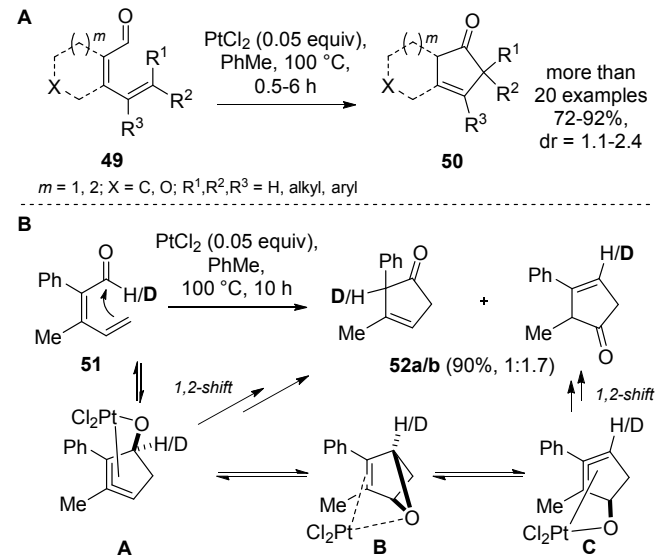

Scheme 12. Iso-Nazarov cycloisomerization of cis-dienals.

Since the work of Denmark, the next example of an iso-Nazarov reaction involving a dienyl-ketone was provided by Sarpong, Tantillo and co-workers. ${ }^{29}$ As a means to access natural product tetrapetalone A, the researchers studied the Nazarov cyclization of aryl dienyl ketones for the synthesis of indanones. As shown in Scheme 13A, many substrates succumbed to this cycloisomerization upon treatment with Lewis acid $\mathrm{AlCl}_{3}$, provided steric and electronic effects were carefully controlled. For example, the presence of the $\alpha$ methyl substituent at the dienyl moiety was mandatory for the success of the process. Surprisingly, analogous substrate $\mathbf{5 5}$ which does not bear an electron-rich aromatic group exclusively underwent an iso-Nazarov reaction with migration of the tolyl group to afford 3-cyclopentenone 57 (Scheme 13B).

A
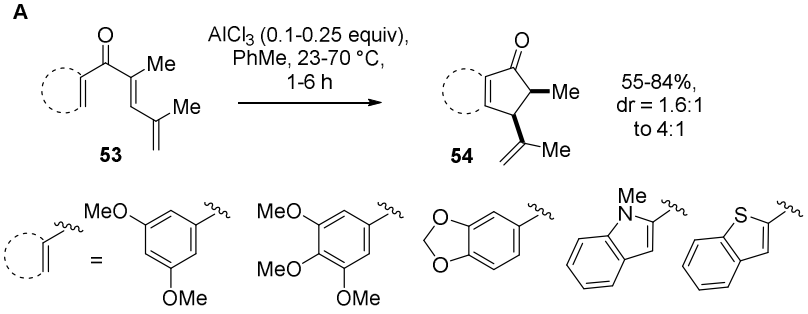

B

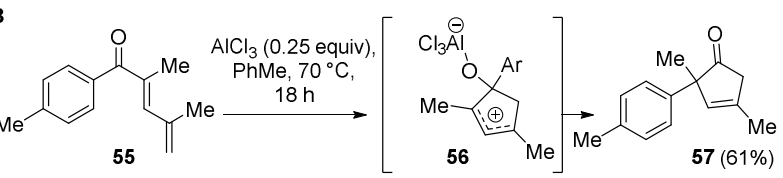

Scheme 13. Iso-Nazarov cyclization of an aryl dienyl ketone promoted by $\mathrm{AlCl}_{3}$.

Jagdale and Youn reported the catalytic iso-Nazarov cyclization of 2-alkenylphenyl carbonyl compounds (58) including aldehydes, ketones and $\beta$-ketoesters (Scheme 14A). ${ }^{30}$ The process was found to be catalyzed by $\mathrm{Au}^{\prime}$ catalysts and this was unexpected since these species are well known to act as soft $\pi$-philic activators. Indeed, several Lewis acidic metal salts as well as many Brønsted acids were tested without success. Ag, Cu and Pt salts did promoted the cyclization. Depending on the nature of the substrates, different classes of products were obtained including indenes, indenols and indanones. Ketones and $\beta$-ketoesters 
delivered indene-type products 60 after dehydration of the corresponding indenol intermediates of type 59 (Scheme 14B). The reactions were in general stereoselective affording in most cases products 60 as the $E$ isomers only. Interestingly, substrates bearing an electron-rich alkenyl side-chain indeed underwent the originally expected transformation involving the activation of the olefin moiety followed by C-attack from the dicarbonyl nucleophilic group (Scheme 14C). Tetralones 61 thus obtained were isolated as mixtures of ketoand enol-tautomers. Benzaldehydes in general required harsh reaction conditions and this was circumvented by using an electron deficient ligand for the catalyst (Scheme 14D). Alkenols 59 were obtained as products except when electron-rich alkenyl side-chains were present. For these substrates $58 \mathrm{c}$, alkenols 59 underwent partial or complete isomerization to the corresponding cyclopentenones 62 . In these cases it is clear that the presence of the aromatic ring next to the carbonyl group prevents any 1,2-group migration (compare cation $\mathbf{B}$ in Scheme 14A with cation 8 in Scheme 1B).

A

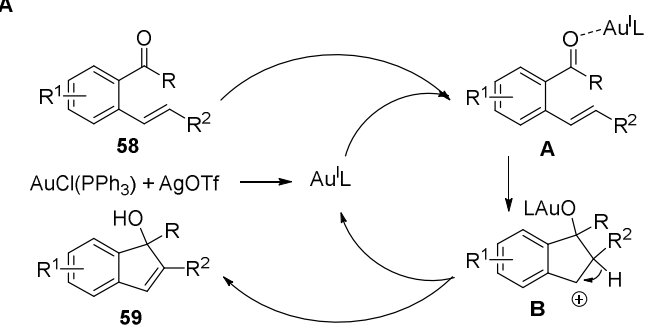

B
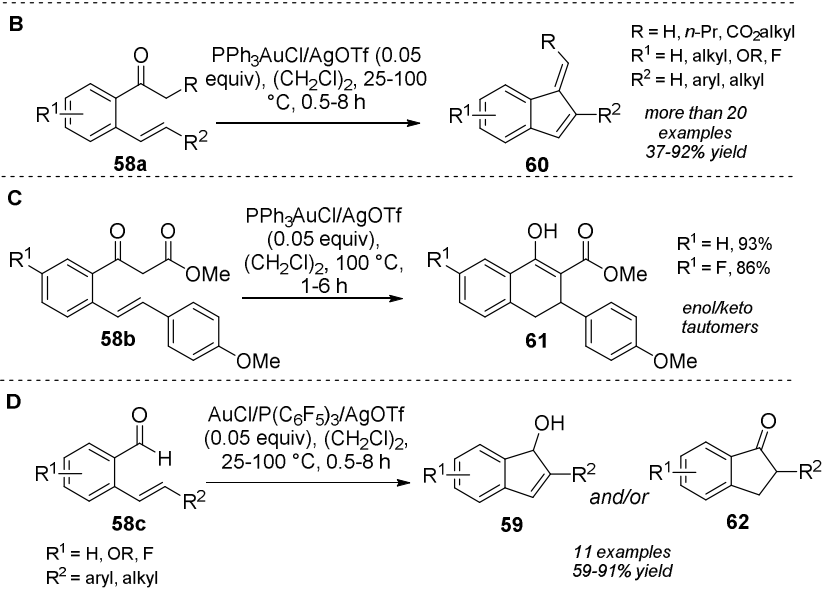

Scheme 14. $\mathrm{Au}(\mathrm{I})$-catalyzed cyclization of 2-alkenylphenyl carbonyl compounds.

The group of Narasaka also employed 2-alkenylphenyl ketones and aldehydes (63) as substrates of a recently reported catalytic transformation in which polycyclic arenes (64) are prepared (Scheme 15A). ${ }^{31}$ Both $\mathrm{Cu}(\mathrm{OTf})_{2}$ and triflic acid were found to achieve best results unlike $\mathrm{BF}_{3} . \mathrm{OEt}_{2}$ or $\mathrm{SnCl}_{4}$ that only provided the desired products in less than $10 \%$ yields. Interestingly, while 2 -cyclohexylidenemethyl-benzaldehyde $\left[\mathrm{R}^{1}=\mathrm{H}\right.$; $\left.\mathrm{R}^{2}, \mathrm{R}^{3}=\left(\mathrm{CH}_{2}\right)_{4}\right]$ provided the corresponding polycyclic product of type 64 in $60 \%$ yield (not shown), 2cyclobutylidenemethyl-benzaldehyde (63a) failed to undergo such transformation (Scheme 15B). Instead, indanone 65a was obtained in almost quantitative yield. The unexpected result was interpreted as arising from an iso-Nazarov reaction of 63 a followed by group migrations promoted by strain release (Scheme 15C). The 
developed transformation towards 64 relies instead on the formation of trienes 67 that undergo a $6 \pi$ electrocyclization and an eventual aromatization.

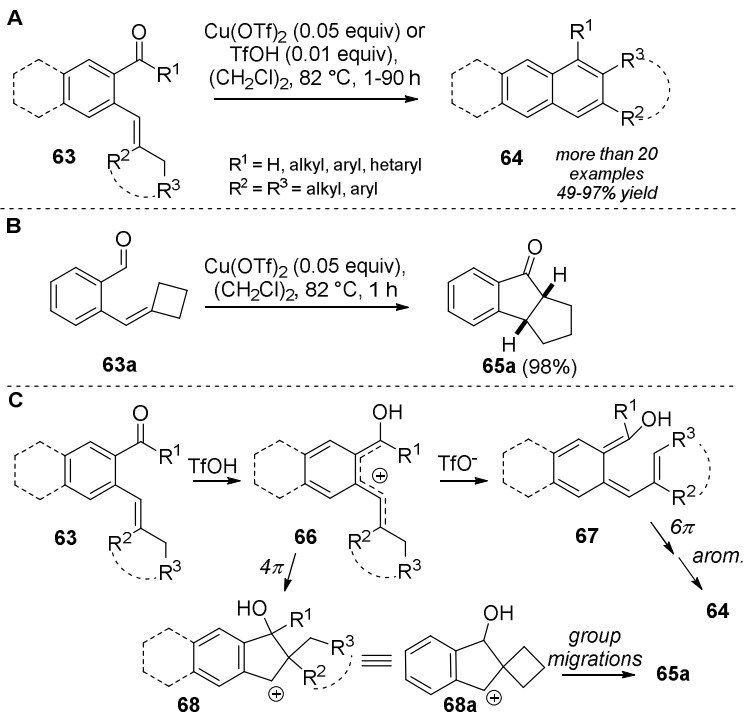

Scheme 15. Iso-Nazarov cycloisomerization of 2-cyclobutylidenemethyl-benzaldehyde (63a).

Due to the importance of five-membered rings, the iso-Nazarov reaction is more than attractive and many more striking examples will be discussed in the following sections. Notwithstanding this, it is clear that the reaction has not reached a mature state. Whereas cis-dienals were found to react more readily than their corresponding isomers, it is not wholly understood whether this is a strict structural requirement. This is important considering all-trans-dienals are synthesized more easily. The reasons to why many substrates do not engage in the process also remain unclear (for example 22 with $R^{2}=$ Me or Ph, 27d and 33). 2Cyclopentenones seem to be the ultimate thermodynamic products and still in some cases these do not form (even at $100 \mathrm{C}$ for many hours). A thorough survey of catalysts as well as a strict exploration of structural and electronic requirements is lacking. More importantly, it would be priceless to test if these reactions can be rendered enantioselective by the evaluation of quiral Lewis acids. As shown, examples of dienoates suffering this type of cyclization have not been reported so far. In this context, Kuroda and co-workers found that upon treatment with triflic acid, both $\alpha$-trimethylsilylmethyl-dienoates and -dienoic acids (69) do not give rise to cyclopentenones $(\mathbf{7 0})$ but to $\alpha$-methylene- $\gamma$-lactones $(\mathbf{7 1}$, Scheme $16 \mathrm{~A}){ }^{32}$ The reaction was proposed to proceed via initial protonation of the $\gamma, \delta$-olefin moiety followed by intramolecular attack of the carbonyl oxygen atom. 


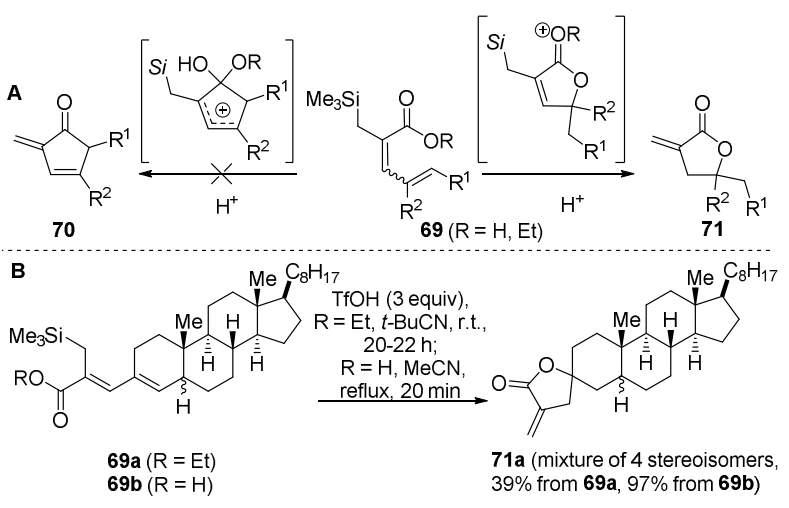

Scheme 16. Cyclization of dienoates and dienoic acids.

\section{Domino or Cascade Processes Involving Iso-Nazarov Reactions}

A domino reaction has been defined by Tietze as a process involving two or more bond-forming or breaking transformations which take place under the same reaction conditions, without any further addition of reagents or catalysts, and in which the subsequent reactions result as a consequence of the functionality formed in each previous step. ${ }^{33}$ Basically, the essence of this class of chemical transformation is to provide molecular complexity in an operationally simple and environmentally friendly fashion; pretty much the way Nature conceives its precious molecules.

It is somewhat extraordinary to find that there have been more examples of domino reactions involving iso-Nazarov processes than pure iso-Nazarov transformations themselves. Whereas some examples have already been disclosed, many more will be depicted here and some will be specially discussed in the following sections.

As early as in 1964, Bodendorf and Mayer reported that under Vilsmeier-Haack reaction conditions at $100 \mathrm{C}$, ketone 72 was converted to hydrochloride 74 in $75 \%$ yield (Scheme 17) ${ }^{34}$ The originally expected cinnamaldehyde $\mathbf{7 5}$ was isolated as product as long as the reaction was kept at $60{ }^{\circ} \mathrm{C}$. The formation of $\mathbf{7 4}$ can be explained by an iso-Nazarov cyclization of intermediate chloroiminium salt $\mathbf{7 3}$. The cyclization can intuitively be regarded as an electrophilic aromatic substitution. More recently, Fan and co-workers explored the $\mathrm{FeCl}_{3}$ catalyzed iso-Nazarov cyclization of iminium ions of type 73 prepared by condensation of sulfonamides and unsaturated aldehydes. ${ }^{35}$

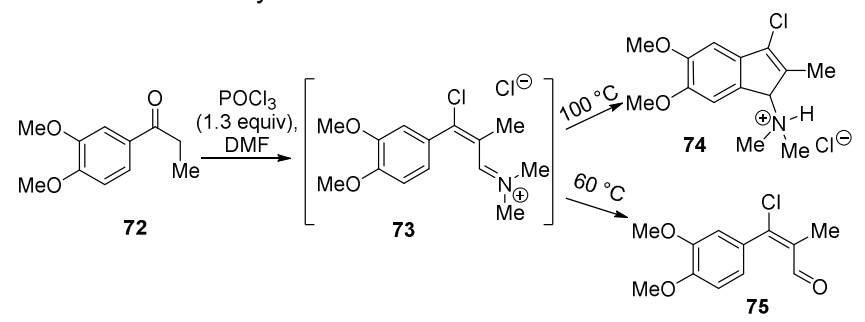

Scheme 17. Cyclization of a cinnamaldehyde derivative. 
Shudo and co-workers reported a domino iso-Nazarov-type cyclization/arene trapping reaction also involving cinnamaldehydes and related chalcones. ${ }^{36}$ As shown in Scheme 18, cinnamaldehyde and 4-phenyl3-buten-2-one were converted to the corresponding phenyl-indenes (78 and/or 79 ) upon treatment with triflic acid in benzene.

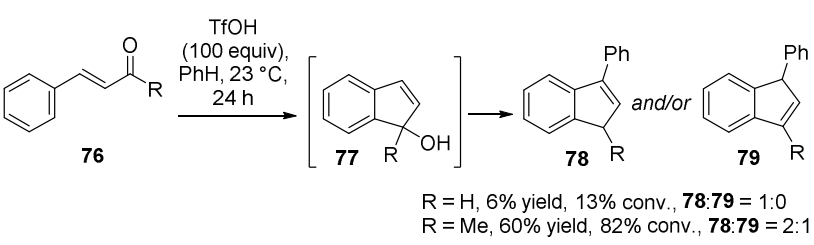

Scheme 18. Domino iso-Nazarov/arene trapping sequence.

In 2006, Sarpong's group reported an impressive Pt-catalyzed rearrangement of epoxy-propargylic esters 80 to cyclopentenones 81 involving an iso-Nazarov reaction (Scheme 19A). ${ }^{37}$ The mechanistic proposal is depicted in Scheme 19B and begins with a Pt-catalyzed 5-exo-dig cyclization to afford intermediate 82 which delivers metallocarbenoid $\mathbf{8 3}$ after rearrangement. Attack by the epoxide produces a labile intermediate (84) that upon ring-opening delivers $2 H$-pyran 85 . Isomerization by means of a oxa- $6 \pi$ electrocyclic reaction would then provide dienone $\mathbf{8 6}$ prone to an iso-Nazarov cycloisomerization upon activation by the Lewis acid thus forming products 81 stereoselectively. Intermediates 85 and $\mathbf{8 6}$ could be isolated in some cases which supports the devised mechanism. More recently, the developed cascade was further investigated by Nieto Faza and de Lera both experimentally and computationally. ${ }^{38}$

A
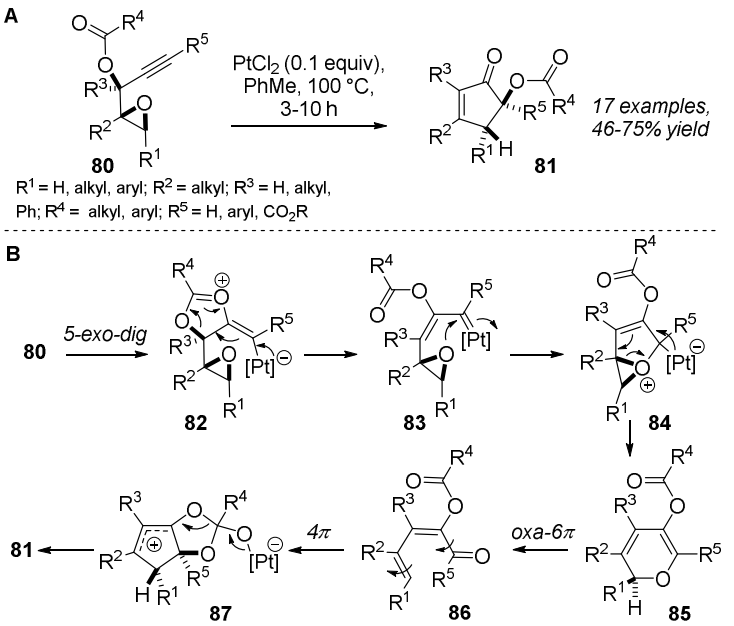

Scheme 19. Rearrangement of oxyranylpropargylic esters to cyclopentenones.

After their original report on the cyclization of cis-dienals to cyclopentenones (Scheme 12), the group of Liu then published a spectacular domino reaction initiated by an iso-Nazarov process (Scheme 20A). ${ }^{39,40}$ More than 80 complex cyclopentene systems were prepared via this interesting transformation baptized as the deoxygenative-iso-Nazarov reaction and which relies on $\mathrm{Au}^{\prime}$ to allow the sequential generation of two allylic carbocations that can be trapped by a plethora of different nucleophiles. As shown in Scheme $20 \mathrm{~B}$, for example, aldehyde $\mathbf{8 8 a}$ can engage in different modes of cyclization such as [4+2], [4+3] and [3+2]-annulations 
as well as in the construction of C-N, C-S, C-O, C-H bonds leading to diverse and complex systems. The enantioselective version of the process was also demonstrated and as shown in Scheme $20 \mathrm{C}$ substrate $88 \mathrm{~b}$ gave rise to product $\mathbf{8 9} \mathbf{f}$ which was obtained with excellent ee provided a chiral ligand was used in the catalytic system. The proposed mechanism for this transformation, which can also be applied to the other modes of cyclization, begins with a Au' catalyzed iso-Nazarov reaction (Scheme 20C). Cation $\mathbf{A}$ thus formed then suffers a stereoselective attack by allylsilane to afford intermediate B. After metal exchange by the olefin coordinated $\mathrm{SiMe}_{3}$ cation, deoxygenation follows thus releasing a brand new allylic cation $\mathbf{D} .{ }^{41}$ A second nucleophilic attack by allylsilane from the less-hindered face provides access to the cyclopentene product $89 \mathrm{f}$ and the active catalyst via generation of by-product $\left(\mathrm{Me}_{3} \mathrm{Si}\right)_{2} \mathrm{O}$.

As a proof of the versatility of the methodology, some members of the brazilane family of natural products were also synthesized (Scheme 20D). For instance, brazilane (97) could be prepared via the deoxygenative iso-Nazarov reaction, one of the nucleophiles being $\mathrm{Et}_{3} \mathrm{SiH}$ and the other being already present in the conveniently functionalized starting dienal $\mathbf{8 8 c}$, i.e. the electron-rich aromatic nucleus. Final removal of protecting groups by $\mathrm{BBr}_{3}$ furnishes natural product 97 in $50 \%$ overall yield.

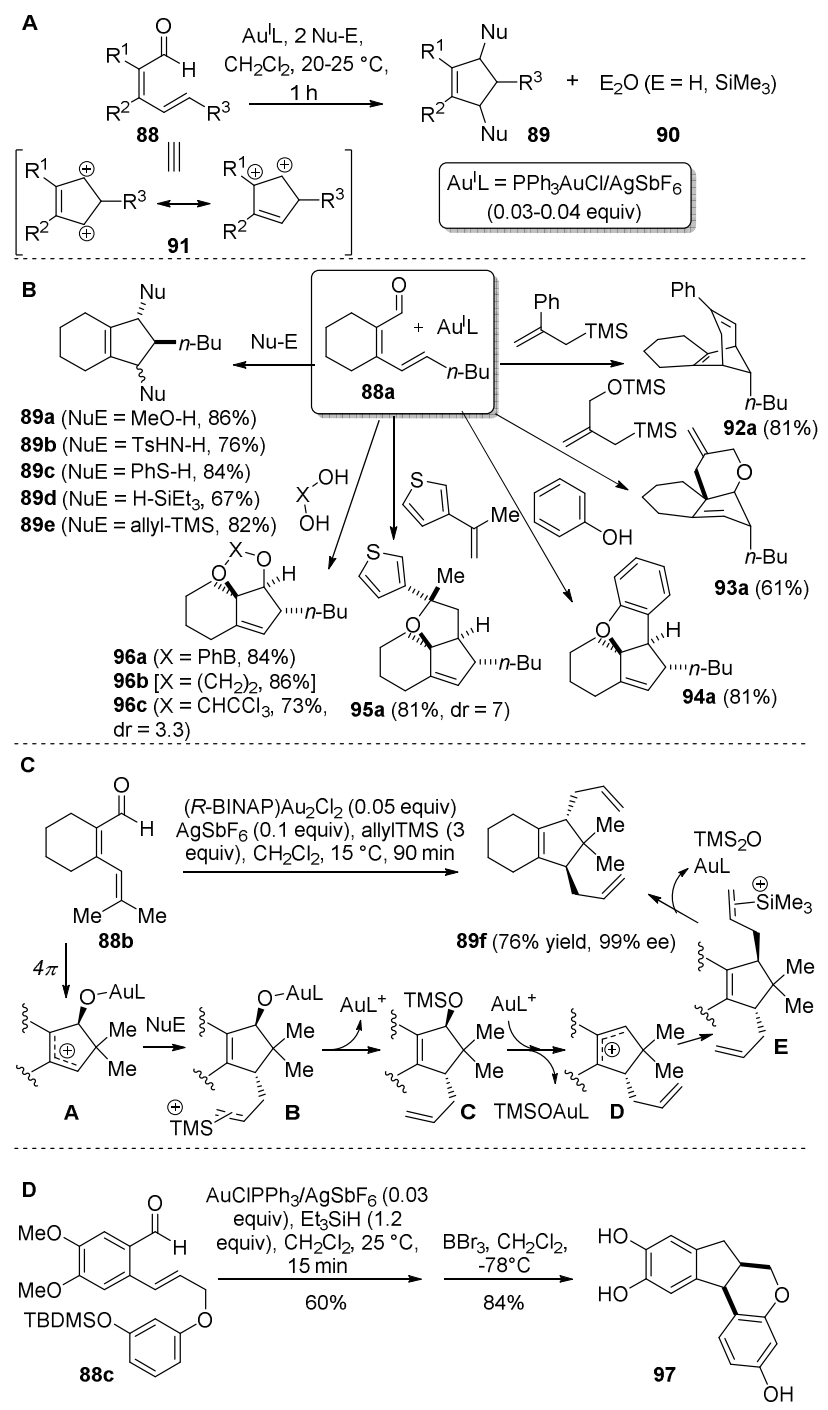

Scheme 20. Domino gold-catalyzed deoxygenative iso-Nazarov reaction of 2,4-dienals. 
During their studies on the preparation of the antitumor agents tedanolides, Jung and Yoo prepared tetrahydrofuran 98 as a potential intermediate in their synthesis (Scheme $21 \mathrm{~A}$ ). ${ }^{42}$ To the surprise of the researchers, this intermediate proved to be unstable and after standing in the absence of solvent for five days it rearranged to cyclopentenone product 99 . The transformation was proposed to be caused by traces of acid or aluminum salts present in the sample since $\mathbf{9 8}$ had been prepared by DIBAL reduction of the corresponding ester. The proposed mechanism for the transformation is depicted in Scheme 21B and involves an iso-Nazarov reaction as key step. cis-Dienal $\mathbf{1 0 2}$ is produced via rearrangement of substrate $\mathbf{9 8}$ and loss of hydrogen bromide. After iso-Nazarov cycloisomerization and further isomerization to the stable cyclopentenone $\mathbf{1 0 5}$ (tetra-substituted alkene isomer), $\mathrm{HBr}$ converts the primary alcohol to the final bromide 99. Interestingly, the transformation also took place when compound 98 was treated with Lewis acid $\mathrm{Me}_{2} \mathrm{AlCl}$ at $23{ }^{\complement} \mathrm{C}$ for 5 days, albeit a lower yield of the dehydration product 99 was obtained (30\%). Moreover, when pure 98 was treated with a catalytic amount of DIBAL, cyclopentenone product 99 could be obtained in $50 \%$ yield. Stopping the reaction before completion allowed the group to find small amounts of intermediates 104 and 105.

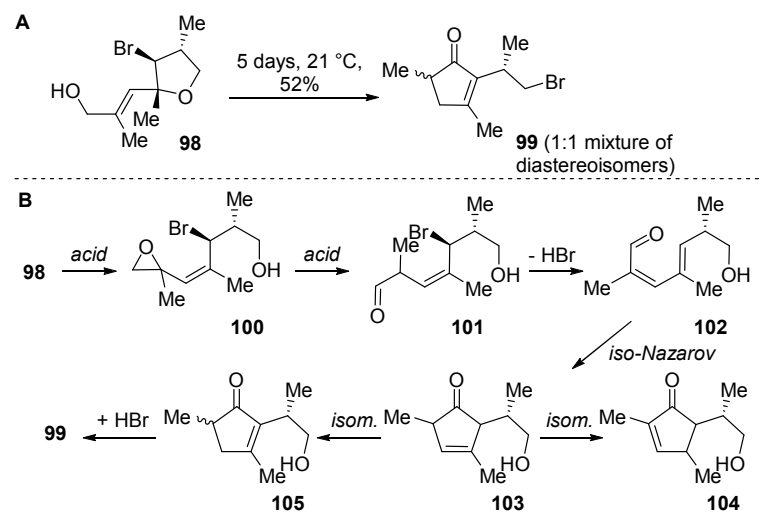

Scheme 21. A rearrangement involving an iso-Nazarov reaction.

Heck and co-workers developed a domino double-aldol-condensation/iso-Nazarov cycloisomerization for the synthesis of cyclopentenones (Scheme 22). ${ }^{43,44}$ Both propionaldehyde and butyraldehyde (106 with $\mathrm{R}^{1}$ $=\mathrm{Me}$ and Et, respectively) were found to undergo self-trimerization when treated with equimolar amounts of dibromotriphenylphosphorane reagent $\left(\mathrm{PPh}_{3} \mathrm{Br}_{2}\right)$ to afford the corresponding cyclopentenones 108a/b in moderate yields. As a mechanistic rationale, an initial double aldol condensation was proposed to provide the corresponding dienal intermediates $\mathbf{1 0 7}$ which under the reaction conditions would undergo an Iso-Nazarov reaction. The process was then extended to a domino cross-aldol condensation/iso-Nazarov process in order to provide structural diversity. Hence, aliphatic aldehydes (106) and $\alpha, \beta$-unsaturated aldehydes (109) were subjected to the same reaction conditions to provide other cyclopentenone products (110). In every case, the cyclopentenone products obtained were those bearing the double bonds with the highest degree of substitution arising from isomerization under the reaction conditions.

The group of Frontier developed a riveting iso-Nazarov domino process initiated by 1,6-conjugate addition that provides access to 5-hydroxycyclopentenones (Scheme 23A). ${ }^{45-47}$ Upon 1,6-conjugate addition of a nucleophile (malonates, primary and secondary amines), dienyldiketones 111 furnish intermediates 113 bearing a linearly-conjugated dienone motif prone to $4 \pi$-electrocyclization (Scheme 23B). This stereoselective process, catalyzed by minimal amounts of Lewis acid, delivers valuable $\alpha$-hydroxycyclopentenone products 
112 in high yields. Further studies revealed that in most cases the reaction could even work in the absence of any acid catalyst or additive. ${ }^{48}$
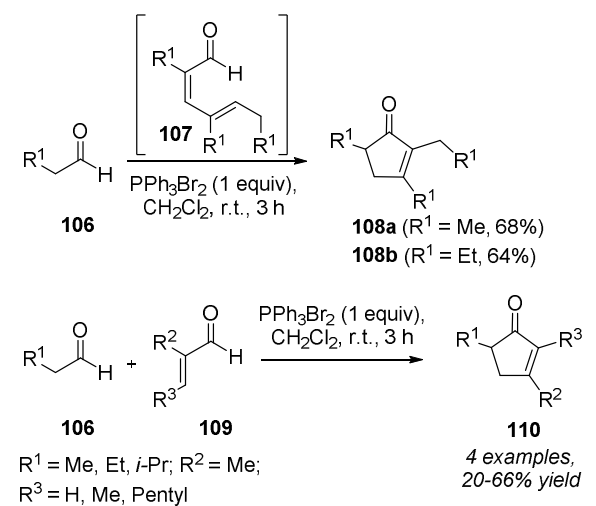
$20-66 \%$ yield

Scheme 22. Domino aldol condensation/iso-Nazarov reaction of aldehydes promoted by $\mathrm{PPh}_{3} \mathrm{Br}_{2}$.

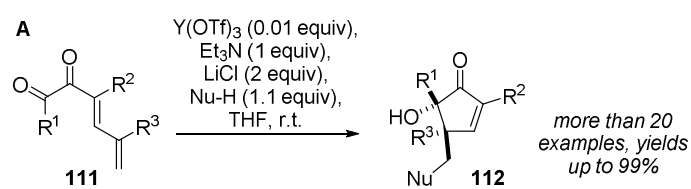

$$
\mathrm{R}^{1}=\text { alkyl, aryl; } \mathrm{R}^{2}=\text { aryl, alkyl, } \mathrm{R}^{3}=\mathrm{H} \text {, alkyl; } \mathrm{Nu}-\mathrm{H}=\mathrm{RO}_{2} \mathrm{C}_{\mathrm{R}}^{\mathrm{CO}_{2} \mathrm{R}}, \mathrm{RR} \mathrm{NH}^{\prime}
$$

Scheme 23. A 1,6-conjugate addition-initiated domino iso-Nazarov reaction.

In addition, the authors found that by using a tertiary amine such as DABCO for the nucleophilic role, the process can deliver either the $\gamma$-methylene cyclopentenone isomers of the starting substrates (114) or the corresponding $2 \mathrm{H}$-pyran isomers (115, Scheme 24). ${ }^{48}$ The former products are formed as a result of an elimination step in now zwitterionic intermediates 112 formed after initial conjugate addition and ensuing $4 \pi$ cyclization. When no hydrogen atom can be eliminated then retro-electrocyclization can provide $Z$-isomers of the starting dienyl-diketones 111 which can undergo an oxa-6 $\pi$ cyclization to provide the $2 H$-pyran products 115. In particular, the domino conjugate addition/iso-Nazarov cyclization/elimination sequence could be rendered enantioselective by using a chiral tertiary amine (Scheme $24 \mathrm{~B}$ ). ${ }^{49}$ For example, under optimized conditions using Hatakeyama's cinchona alkaloid 116, cyclopentenone 114a was obtained in 88\% yield and with excellent enantiomeric excess.

The same group recently expanded their original domino sequence to provide access to complex $N$ containing bicyclic systems. ${ }^{50}$ By using $\alpha$-methylene or $\alpha$-methine amines as nucleophiles, diketones 117 yield the corresponding cyclopentenone products $\mathbf{1 1 8}$ that can still engage in a thermal redox cyclization upon thermal treatment (Scheme 25). This intramolecular final annulation sequence would comprise a hydride 
transfer step (118 to 119) followed by a Mannich ring-closure (119 to $\mathbf{1 2 0}$ ) and in this manner the whole transformation installs two cycles and up to four stereogenic centers. In some cases, the use of Lewis acid $\mathrm{Y}(\mathrm{OTf})_{3}$ and an amine base was necessary to trigger this fascinating sequence.

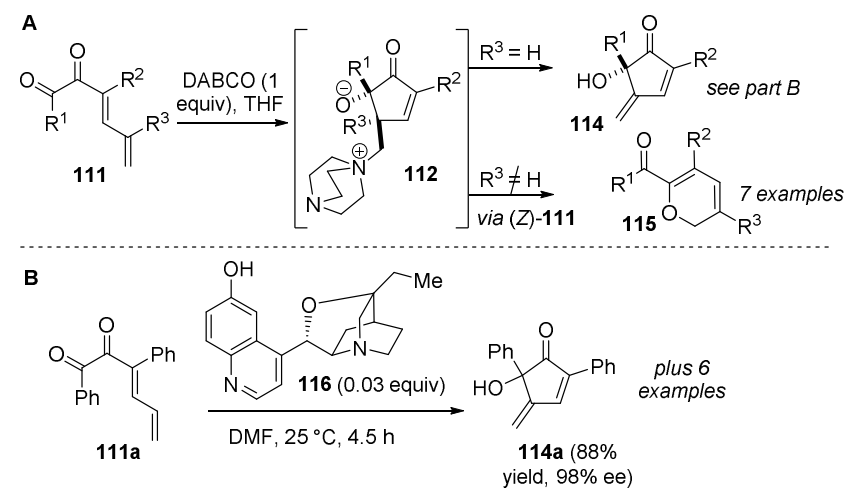

Scheme 24. Alternative 1,6-conjugate addition-initiated domino processes.

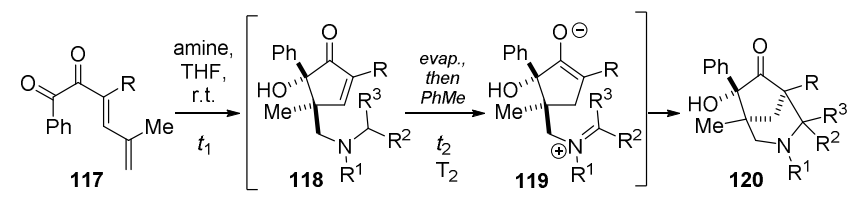

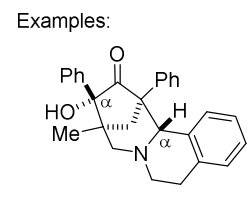

120a (84\%): $20 \mathrm{~min}$, then $18 \mathrm{~h}\left(160^{\circ} \mathrm{C}\right), 5: 1(\alpha \alpha / \beta \alpha)$

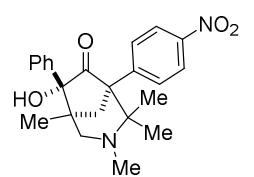

$\mathrm{Me}$

120b (43\%): $20 \mathrm{~min}$ then 3 days $\left(50^{\circ} \mathrm{C}\right)$

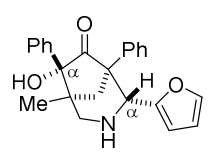

120c (50\%): $21 \mathrm{~h}$, then $24 \mathrm{~h}$ $\left(160^{\circ} \mathrm{C}\right), 1: 1(\alpha \alpha / \alpha \beta)$

Scheme 25. Domino 1,6-conjugate addition/iso-Nazarov/internal redox cyclization sequence.

In 1984, during their studies on the chemistry of 5-ylidene- 1,3-dioxolan-4-ones, the group of Ramage obtained the cyclopentenone product 122 and the expected aldehyde 123 upon DIBALH reduction of substrate 121 (Scheme 26A). ${ }^{51}$ Whereas no interpretation was given at the time, the formation of 122 can be understood as a result of a domino reduction/iso-Nazarov reaction of an oxocarbenium intermediate derived from the reduction of $(E)-121(124) .^{52}$ Many years later, this process was studied by Li and co-workers who elegantly applied it to the synthesis of notable alkaloid cephalotaxine as well as many interesting 5-hydroxycyclopentenones (Scheme 26B). ${ }^{53}$ Not only dioxolanones were prone to the developed cascade but also other substrates such as Weinreb amides (e.g. 129) and $\alpha$-alkoxydienoates (e.g. 130, Scheme 26C). ${ }^{54}$ Notwithstanding this, in all cases best results were obtained starting from dioxolanones such as 128, supporting the intermediacy of cationic species of type 124 in a facilitated iso-Nazarov cyclization. The stereochemistry of the substrates was crucial for the success of the devised process, named by the research group as the reductive oxy-Nazarov cyclization, since the use of (2Z)-128 and (2Z)-129 only delivered the corresponding dienal upon reduction with DIBALH and the use of ester (2Z)-130 led to the formation of the corresponding dienyl alcohol. 


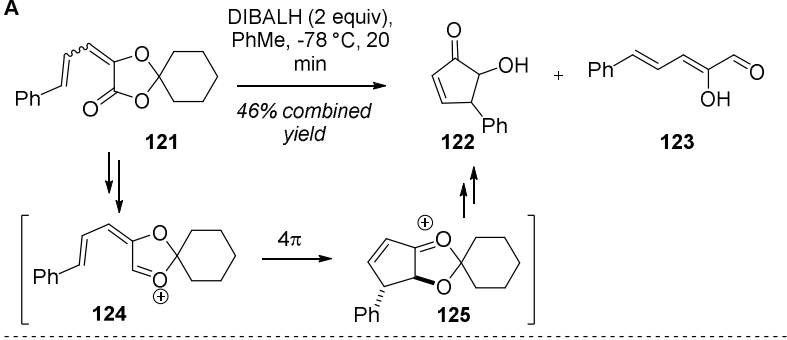

B

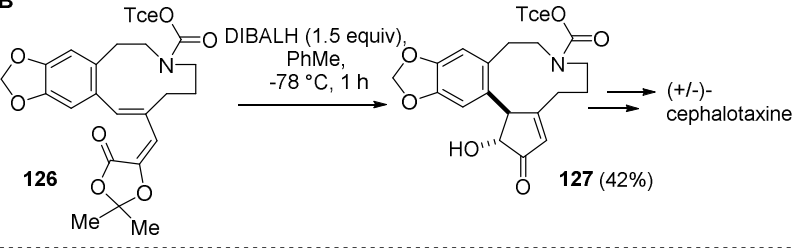

C

2-BrPh (2E)-128

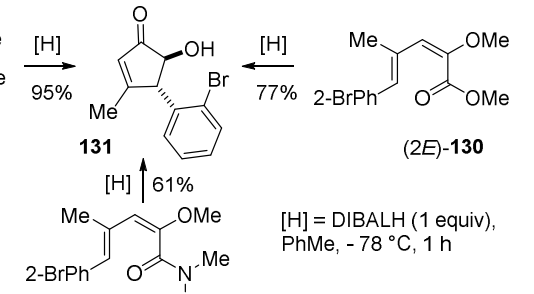

(2E)-129 OेMe

Scheme 26. Domino reduction/iso-Nazarov process. Tce $=2,2,2$-trichloroethyl.

A neutral Nazarov reaction catalyzed by $\mathrm{Pd}(0)$ was recently reported by Tius and co-workers. ${ }^{55}$ Treatment of diketones 132 with small amounts of the $\mathrm{Pd}_{2}(\mathrm{dba})_{3} / \mathrm{PPh}_{3}$ catalytic system affords cyclopentenones 133 in good yields and with complete diastereoselectivity (Scheme 27A). Substrate 132a, in particular, did not participate in the developed process but underwent an iso-Nazarov reaction towards cyclopentenone 134a presumably via the intermediacy of tautomeric dienol 135a (Scheme 27B). Since another substrate with both $\mathrm{R}^{1}$ and $\mathrm{R}^{2}$ as methyl groups underwent the "expected" Nazarov mode of cyclization, the authors considered the phenyl group to be responsible for the unexpected outcome of the reaction of 132a. The reaction can as well be viewed as an intramolecular vinylogous aldol reaction on intermediate 135a.

A

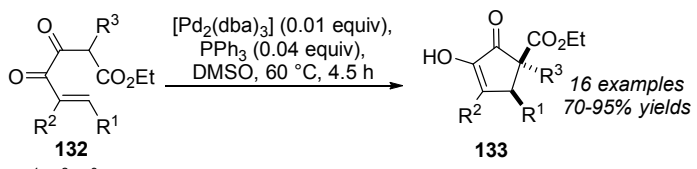

$R^{1}, R^{2}, R^{3}=$ alkyl, aryl

B

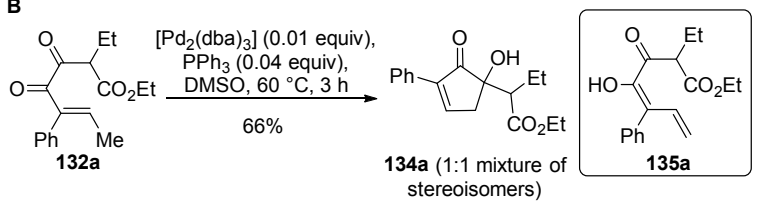

Scheme 27. Pd-catalyzed iso-Nazarov reaction of diketoester 132a.

The group of Zhang recently reported the synthesis of 4-aminocyclopentenones from glycals and arylor heteroaryl amines (Scheme 28A). ${ }^{56-57}$ These particular cyclopentenone scaffolds are not only attractive due 
to their antiviral properties but also because they serve as building blocks for the construction of 4aminocarbocyclic nucleosides as analogues of some antiviral drugs. The research group proposed 1aminopentadienyl cation 138 as key intermediate that would deliver products 139 after $4 \pi$-conrotatory ring closure. ${ }^{58}$ Based on these and other observations, the group of Liu later introduced the imino-iso-Nazarov reaction (Scheme 28B) ${ }^{59}$ Lewis acid $\mathrm{SnCl}_{4}$ (30 mol\%) promotes the condensation of dienal 140 and aniline 141 to provide, after iso-Nazarov cyclization, 4-amino-cyclopentenone 142. Product 142, which is obtained in excellent yield, is found as a single diastereoisomer although a mixture of $E$ and $Z$ isomers of dienal $\mathbf{1 4 0}$ is used in the reaction, suggesting the sole intermediacy of an out,out-U-shaped cyclopentadienyl cation of type 138 due to isomerization. Interestingly, by careful control of the reaction conditions the process can be tamed and further transformations result in novel domino processes (Scheme $28 \mathrm{C}$ ). By running the reaction at higher temperatures and using silver perchlorate as catalyst, 140 and 141 engage in an interrupted imino-iso-Nazarov reaction to provide cyclopentaindole products of type $\mathbf{1 4 3}$ diastereoselectively. Surprisingly, in the presence of lanthanide metal catalysts such as $\mathrm{Gd}(\mathrm{OTf})_{3}$, tetrahydroquinoline-fused cyclopentenones are obtained instead (e.g. 144). As shown in Scheme 28D, after condensation and $4 \pi$-electrocyclization, diastereoselective intramolecular arene trapping on intermediate 146 delivers product 143 after hydrolysis. The formation of 144 from 143 (Scheme 28C) along with deuterium labeling studies prompted the authors to propose an elimination/retro-ene/stereoselective Mannich sequence as mechanistic rationale for the formation of the tetrahydroquinoline products of type 144.

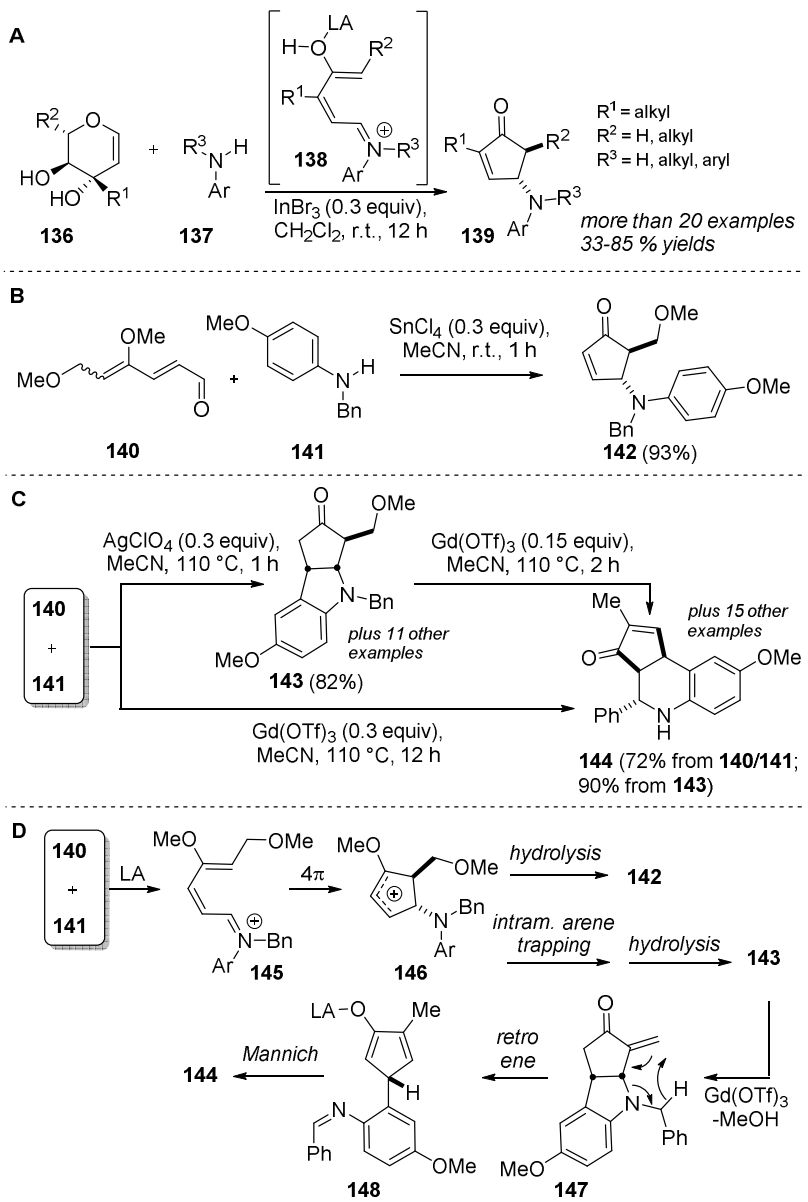


Scheme 28. Imino iso-Nazarov domino processes.

Shortly after their report, and encouraged by the importance of carbocyclic nucleosides, the group of Liu then became interested in intercepting the oxyallyl cation 146 with an external amine nucleophile. These studies gave birth to the intermolecular interrupted imino-iso-Nazarov reaction (Scheme 29$).{ }^{60}$ For example, $\operatorname{InBr}_{3}$ catalyzed coupling of 140 and 141 , in the presence of silylated nucleobase 149, led to the formation of highly functionalized cyclic enol ether $\mathbf{1 5 0}$. The methodology was found to be versatile allowing the preparation of several derivatives with excellent yields. In all cases, the carbocyclic nucleoside analogues were obtained as single diastereoisomers arising from selective nucleophilic attack by the silylated nucleobases on the opposite side of that occupied by the amino group at C-4.

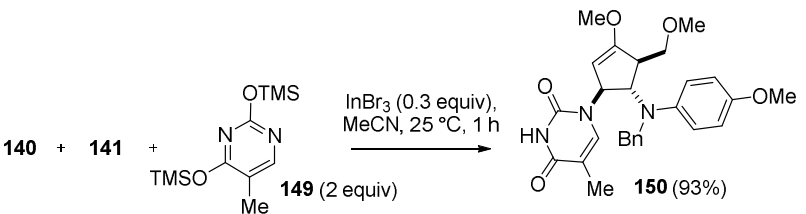

Scheme 29. Intermolecular interrupted imino iso-Nazarov domino process.

Another example of an interrupted iso-Nazarov reaction was recently provided by the groups of Moreau and Vincent. ${ }^{61}$ Cyclic oxyallyl cations (153) obtained via iso-Nazarov cyclization of the corresponding dienals (152) can be intercepted by different $N$-acetyl indoles (151) in a dearomative [3+2] cycloaddition that provides indoline-based complex architectures with high diastereoselectivities (154 and 155, Scheme 30). The process was found to be promoted by inexpensive and environmentally benign ferric chloride and in most cases major products were those arising from a reversal of the classical polarity of the C2 and C3-positions on the indoles (154) as a consequence of Lewis acid activation of $N$-Ac indoles. Curiously enough, unbranched dienals $152\left(R^{4}=H\right)$ did not participate in the reaction with substrates 151.

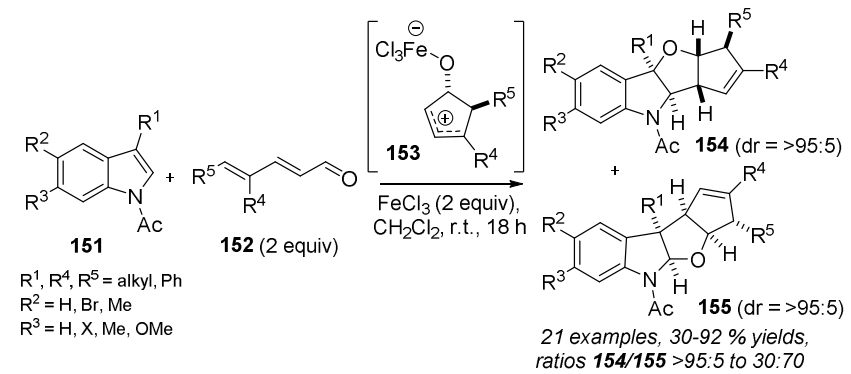

Scheme 30. Intermolecular interrupted iso-Nazarov domino process.

\section{Vinylogous Iso-Nazarov Reactions}

The group of West recently introduced the vinylogous Nazarov reaction (Scheme 31$){ }^{62}$ The acid activation of cross-conjugated trienes of type 156 leads to the formation of the corresponding cyclic isomers 159 via $4 \pi$-electrocyclization at the end of the polyene-carbonyl chain. In an analogous fashion, cycloisomerization processes of linearly-conjugated triene-carbonyl compounds have been as well developed 
by the groups of Valla, Trauner and ours. As shall be seen below, all studies have in common the fact that the $4 \pi \mathrm{e}^{-}$cyclization takes place at the end of the polyene chain and this is consistent with computational studies on 1-hydroxyheptatrienyl cations carried out by de Lera's group. ${ }^{63}$

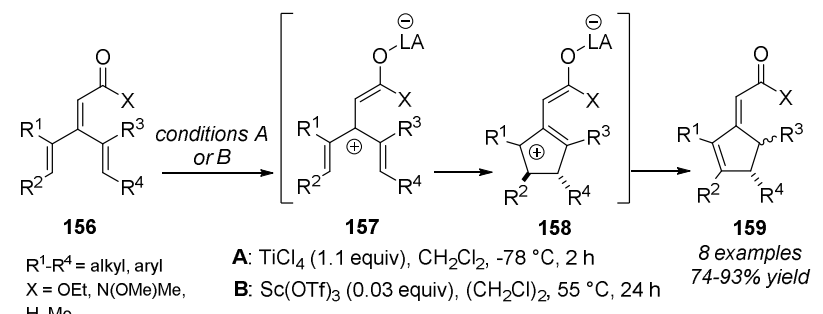
$\mathrm{H}, \mathrm{Me}$

Scheme 31. The vinylogous Nazarov reaction.

Valla and Giraud were the first to report the spectacular cycloisomerization of all- $E$ 2,4,6-trienoic acids 160 to $\gamma$-lactones 161 under neutral conditions (Scheme 32). ${ }^{64}$ At the time, the authors proposed zwitterion 162 as intermediate, which undergoes cyclization to cyclopentenyl cation 163 via a U-form conformation. Trapping of this cation by the carboxylate moiety then furnishes the bicyclic products $\mathbf{1 6 1}$ which were described as single diastereoismers. Almost a decade after their original study the authors further developed the reaction expanding its synthetic scope. ${ }^{65-67}$

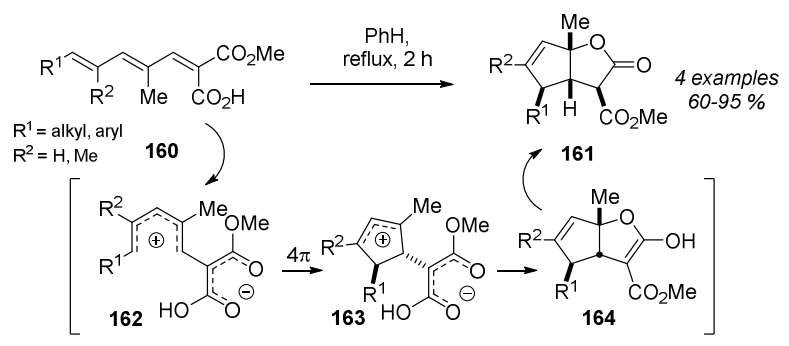

Scheme 32. Formation of $\gamma$-lactones via cycloisomerization of trienoic acids.

Soon after Valla's report on the vinylogous iso-Nazarov transformation of trienoic acids 160, Elia and co-workers reported NMR studies on the isomerization of 2,4,6-octatrienal (165) in $\mathrm{FSO}_{3} \mathrm{H}$, which can be regarded as the first example of a non-interrupted vinylogous iso-Nazarov process (Scheme 33 ). ${ }^{23}$ Protonated 2,4,6-octatrienal (A) undergoes quantitative cycloisomerization to cation $\mathbf{B}$ at temperatures as low as $-20{ }^{\circ}$. Cation B formed as a single stereoisomer according to NOE experiments, delivered dienal 166 upon neutralization. Although a pure sample of $\mathbf{1 6 6}$ could not be obtained (yield not reported either), its identity could be confirmed by comparison of ${ }^{1} \mathrm{H}$ NMR data with reported literature data. A dication intermediate was also proposed as intermediate towards 166.

Another dazzling cycloisomerization was later disclosed by Miller and Trauner. ${ }^{68}$ Lewis acid $\mathrm{Me}_{2} \mathrm{AICl}$ was found to promote a novel Lewis acid-catalyzed process involving the isomerization of trienoates to bicyclo[3.1.0]hex-2-enes, a process we later categorized as an interrupted vinylogous iso-Nazarov reaction. ${ }^{69}$ As shown in Scheme 34A for the synthesis of rac-photodeoxytridachione, polyene precursor 167 delivers 
product 168 as a single stereoisomer. Further elaboration, i.e. the installment of the pyrone moiety, eventually provided natural product 169. In stark contrast to Valla's iso-Nazarov process (Scheme 32), under neutral conditions, i.e. in the absence of $\mathrm{Me}_{2} \mathrm{AICl}$, substrate 167 was found to undergo a thermal disrotatory $6 \pi$ electrocyclization and thus cyclohexenes such as $\mathbf{1 7 0}$ were obtained. The newly discovered process which involves the formation of a strained bicyclic system with four contiguous stereocenters was found to be stereospecific and, for instance, diastereoisomeric 171 provided epimeric 172 as product (Scheme 34B). Shortly after, the reaction was extended to the synthesis of natural (-)-crispatene and biosynthetic implications on these polyketide-derived molluscan natural products were considered. ${ }^{70,71}$ The authors provided two mechanistic scenarios for their fascinating transformation (Scheme 34C). The stepwise mechanism involves initial regioselective $4 \pi$-electrocyclic ring-closure to deliver cation $\mathbf{A}$ that is subsequently trapped in a stereoselective fashion. In this case, rotation about $\mathrm{C} 2-\mathrm{C} 3$ bond is supposed to be slow enough so that the reaction is stereospecific as exemplified for the outcome of using stereoisomeric precursor 171 . The concerted version, on the other hand, is based on the dissection of the polyene chain into tethered diene and dienophile moieties that engage in an intramolecular $\left[{ }_{\pi} 4_{a}+{ }_{\pi} 2_{a}\right]$ cycloaddition. Computational studies on this reaction by de Lera et al. suggest the transformation does not strictly follow neither a concerted nor a stepwise reaction mechanism. ${ }^{72}$ No intermediate is found and the reaction would proceed through initial five-membered ring formation followed by a barrierless creation of the cyclopropane system.

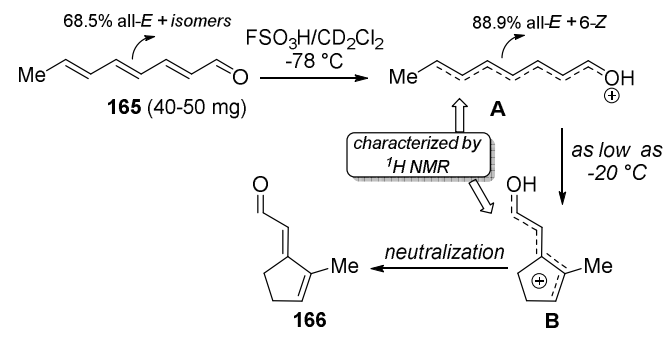

Scheme 33. Regio- and stereoselective cyclization of 2,4,6-octatrienal.
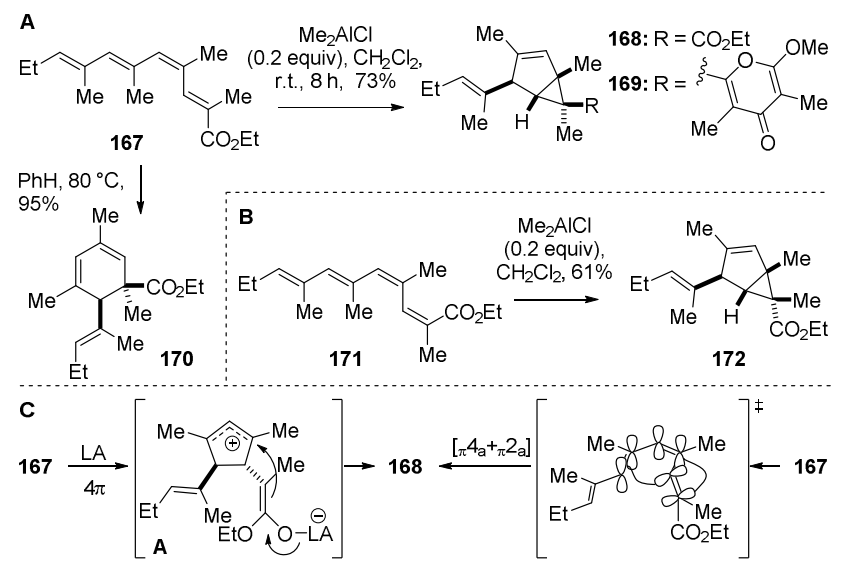

Scheme 34. Lewis acid-catalyzed isomerization of trienoates to bicyclo[3.1.0]hex-2-enes. 
We came across an iso-Nazarov process analogous to the one portrayed above during our studies on the Knoevenagel condensation between dicarbonyl compounds and unsaturated aldehydes. ${ }^{73,74}$ Different cyclic 1,3-dicarbonyl compounds (173) and dienals (174) were found to engage in a cascade process that provides cyclopenta[b]furan derivatives $\mathbf{1 7 5}$ as products (Scheme 35A). Diverse experimental observations led us to propose a domino Knoevenagel/vinylogous-iso-Nazarov pathway to account for the stereoselective formation of products 175 (Scheme 35B). Thus, after condensation and mild-acid activation, conrotatory $4 \pi \mathrm{e}^{-}$ring closure at the end of the polyene chain provides cyclopentenyl cation $\mathbf{C}$ ready for intramolecular capture. In contrast with Trauner's process, in this case, cyclopentenyl cation $\mathbf{C}$ is intramolecularly trapped by enol oxygen atom leading to heterocycle construction instead of carbon-carbon bond formation. Substituents on the polyene chain played a crucial role and mostly $\alpha$-substituted dienals only participated in the reaction. This structural feature was not only supportive of a requirement for instability of the conjugated polyene chain but also seemed to play a cation-stabilizing role. Indeed, the use of $\alpha$-unsubstituted dienals on these condensations delivered classical Knoevenagel products isolated as colorful crystals (e.g. 176, Scheme 35C). Notwithstanding this, the system could have such a fine tuning that for instance branching at the $\varepsilon$-position was enough perturbation to provoke slow cycloisomerization in, for instance, deuterated chloroform (176, $R=M e)$. Whereas this rearrangement was attributed to acid traces present within the deuterated solvent, the cationic Nazarov pathway was later cleanly supported by the finding that stable trienediketones such as $176(R=H)$ rearranged to their polycyclic isomers 177 upon Lewis or Brønsted acid activation (Scheme 35C). ${ }^{69}$ Since we later found that the process could be rendered possible also under neutral conditions (refluxing toluene) we departed from the classical cationic point of view and a pericyclic cascade was elaborated and supported computationally. ${ }^{75}$ This proposal involves an initial isomerization via well-known oxa- $6 \pi$ processes to deliver a reactive intermediate $\left(\gamma, \delta\right.$-Z-A) that undergoes an intramolecular $\left[{ }_{\pi} 4_{s}+_{\pi} 4_{a}\right]$ cycloaddition (Scheme 35D). Indeed, a stable $2 \mathrm{H}$-pyran substrate similar to proposed intermediate D was found to undergo cycloisomerization towards its cyclopenta[b]furan isomer upon both thermal and Lewis-acid treatment.

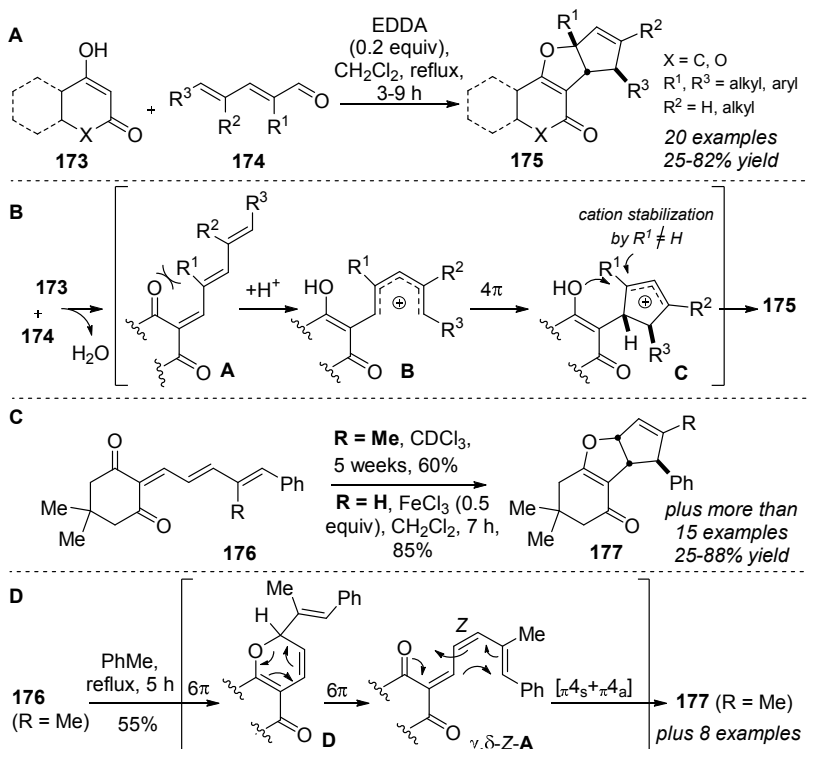

Scheme 35. Interrupted vinylogous iso-Nazarov process for the synthesis of cyclopenta[b]furan derivatives. 
We were somehow pretty sure that, based on the ease with which these polyenes undergo neat and precise polycylizations, this cascade had to be traced in Nature. In this context, we proposed that citridone A (178), a furopyridone belonging to a new family of natural products recently presented by Nobel Laureate $S$. Õmura and co-workers, ${ }^{76-78}$ could be naturally produced via an interrupted vinylogous iso-Nazarov cascade (Scheme 36A). Previous biosynthetic studies on tetramic acid derived natural products suggest that a suitable polyunsaturated precursor such as $\mathbf{1 7 9}$ could be produced from a less-elaborated acyl-tetramic intermediate 180 derived, at the same time, from amino acid phenylalanine and a proper polyketide derivative. The closest solution to this puzzle was provided by Zografos and Fotiadou who carried out the Knoevenagel reaction between phenylpyridone 181 and quiral aldehyde 182 (Scheme 36B). ${ }^{79}$ This condensation led to an unwieldy mixture of products 183 that upon treatment with Lewis acid bismuth triflate provided rac-178 presumably via an intermediate of type $\mathbf{B}$ (Scheme 35B).
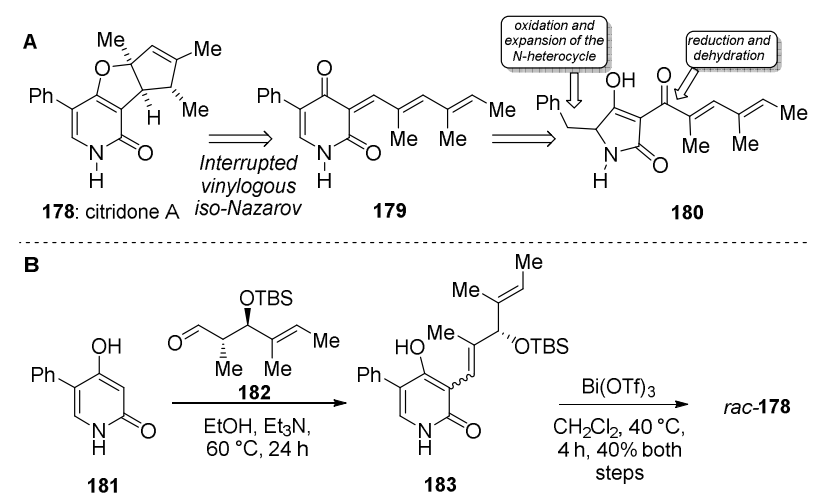

Scheme 36. Possible biosynthetic pathway for alkaloid 178 involving an interrupted vinylogous iso-Nazarov process and synthesis of $\mathbf{1 7 8}$ by Zografos and Fotiadou.

More recently, Lin et al. devised another domino reaction involving a vinylogous iso-Nazarov process that also provides cyclopenta[b]furans as products (Scheme 37 ). ${ }^{80}$ Alkylation of ethyl acetoacetate with different dienyl bromides (185) provides intermediates 186 that upon dehydrogenation with diacetoxyiodobenzene deliver cyclopenta[b]furan derivatives 187 as products. According to the authors, at ambient temperature the conjugated trienedicarbonyl intermediates can be intercepted.

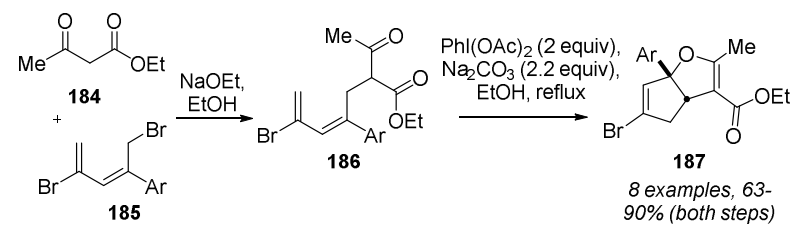

Scheme 37. A domino oxidation-vinylogous iso-Nazarov process for the synthesis of cyclopenta[b]furan derivatives. 


\section{The Piancatelli Reaction}

As the preceding pages show, the number of domino or cascade reactions involving iso-Nazarov steps is large and growing. Notwithstanding this, there is one particular domino iso-Nazarov reaction that has received considerable attention and that is actually a named reaction, i.e. the Piancatelli rearrangement. In 1976, Piancatelli and co-workers reported the acid-catalyzed isomerization of 2-furylcarbinols (188) to 4hydroxycyclopentenones (189, Scheme $38 \mathrm{~A}){ }^{81}$ According to the research group, a possible mechanism to explain this transformation begins with the protonation of starting alcohol 188 followed by loss of water. Oxocarbenium ion 190 thus formed is then trapped by water and this leads to intermediate 191 which gives rise to out,out-cation 192 after acid-promoted ring-opening. Hydroxy-pentadienyl cation 192 would finally undergo $4 \pi$-conrotatory ring closure towards product 189 . It should be noted that although other mechanisms have been as well proposed, computational studies support this iso-Nazarov mechanistic scenario. ${ }^{16 a}$ In addition, Piancatelli and co-workers also observed further rearrangement of products 189 to cyclopentenones 193 during chromatography purification using neutral or basic alumina (Scheme 38A). ${ }^{82}$ Much of the interest in the Piancatelli reaction has lain on the fact that it is a versatile platform for prostaglandin synthesis. ${ }^{83}$ Many members of this class of fatty acid-derived natural bioactive molecules have been prepared via this methodology including analogues commercialized as drugs (Scheme 38B). It is not the purpose of this chapter to cover all the work done on this transformation but to only present its most recent advances. The interested reader should consult some previous reviews available on the subject. ${ }^{84}$

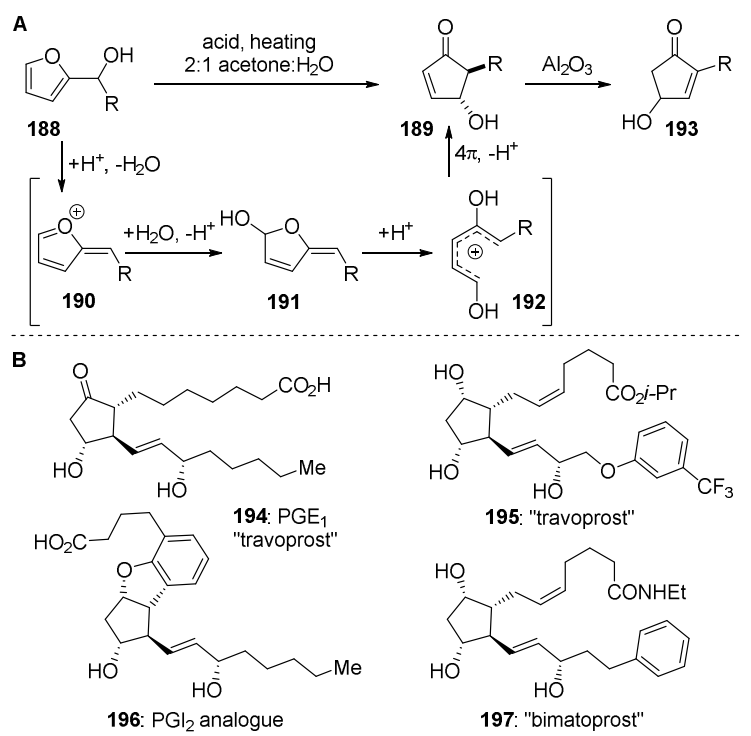

Scheme 38. The Piancatelli rearrangement and some natural prostaglandins or derivatives prepared using this reaction.

Several variants of the reaction including domino and tandem processes based on the Piancatelli reaction have materialized over the past decades (Scheme 39). ${ }^{85-95}$ These include, for example, the application to natural product synthesis other than prostaglandins and the development of both inter- and intramolecular 
interrupted processes based on the trapping of key intermediate 190 by $\mathrm{C}-, \mathrm{N}-$, and O-nucleophiles other than water.

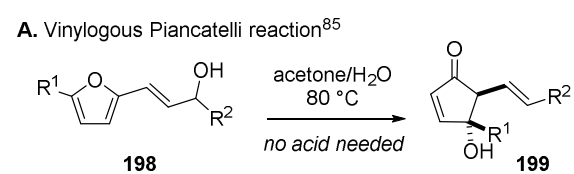

B. Natural target molecules prepared via the Piancatelli reaction ${ }^{86-89}$

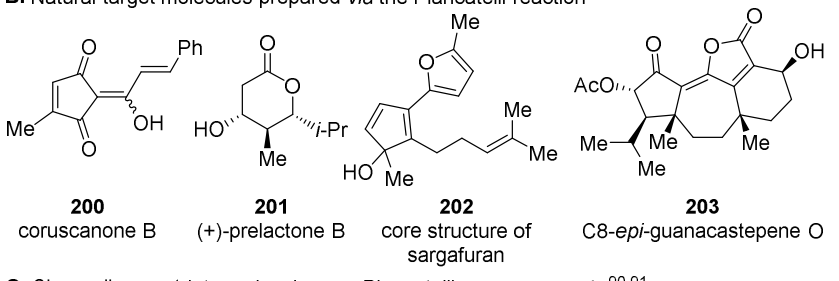

C. Chemodivergent intramolecular oxa-Piancatelli rearrangements ${ }^{90,91}$

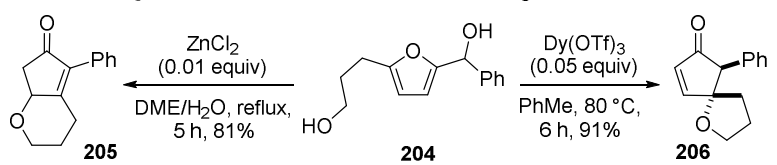

D. Intra- and intermolecular Aza-Piancatelli rearrangement ${ }^{92,93}$

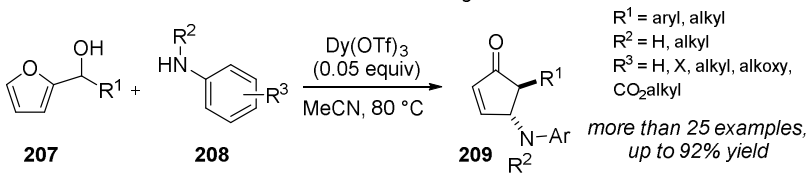

E. Alternative substrates for the Piancatelli rearrangement ${ }^{94}$

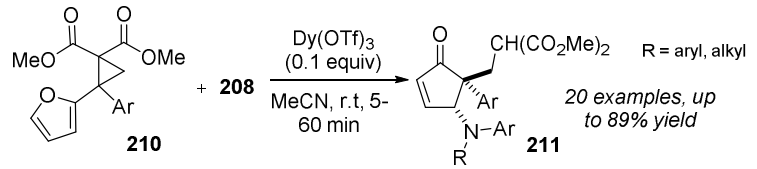

F. Tandem processes based on Piancatelli rearrangements ${ }^{95}$

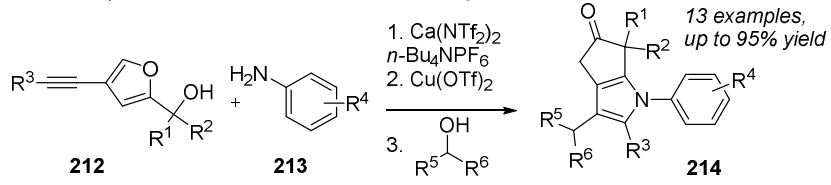

Scheme 39. Some developments on the Piancatelli rearrangement since its discovery.

Most recent breakthrough contributions to the field came to light in 2016 when the groups of Sun ${ }^{96}$ and Rueping ${ }^{97}$ almost simultaneously reported the asymmetric variants of the aza-Piancatelli rearrangement (Schemes 40A and 40B, respectively). Both strategies rely on the use of chiral Brønsted acids 217 and 221 as catalysts to provide priceless enantioenriched 4-aminocyclopentenones (218/222). As shown in Scheme 40C, in the aza-Piancatelli reaction, once key cation intermediate $\mathbf{1 9 0}$ is formed after dehydration of starting 2furylcarbinol 188, intermolecular attack by an amine nucleophile provides hemiaminal 223. This species evolves into 1-amino-pentadienyl cation 224 that after $4 \pi$-electrocyclic ring closure affords 4aminocyclopentenone product 225. By using these chiral acids, hydrogen bonding on intermediates 224 would allow for counter ion/asymmetric induction to operate. ${ }^{98}$ 
A

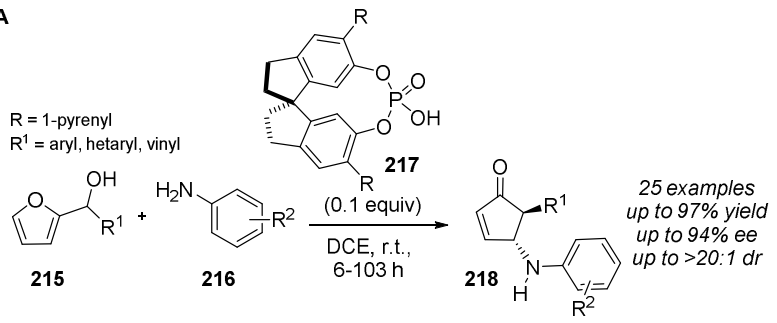

B

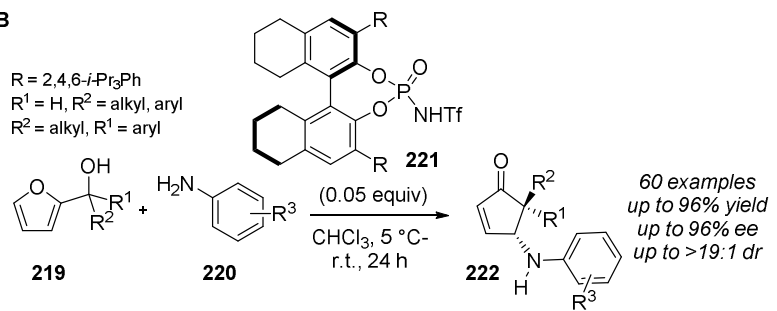

C

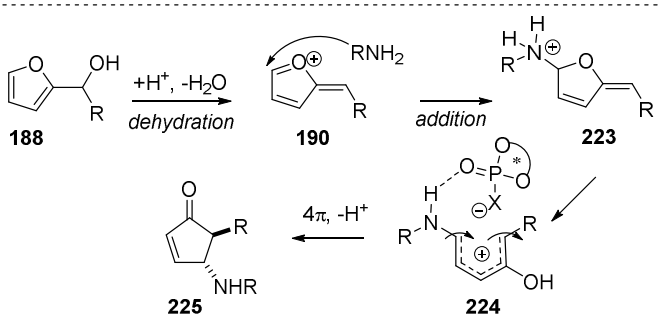

Scheme 40. Catalytic asymmetric aza-Piancatelli rearrangements.

\section{The Iso-Nazarov Reaction in Nature}

Since both polyunsaturated carbonyl compounds and cyclopentenones are common structural motifs amid natural substances, it would not be surprising to find the iso-Nazarov process operates in Nature. Over the years, many pericyclic reactions such as cycloadditions have indeed been found to be part of biosynthetic pathways. ${ }^{99}$ Apart from citridone A (178, Scheme 36 ), for which a vinylogous iso-Nazarov reaction can be proposed to account for its biomimetic synthesis, some more examples can be advanced.

Cephalotaxine ester derivatives are an important class of alkaloids that have aroused considerable attention due to their potent antileukemic activity, one of these, harringtonine, being approved by the FDA in 2012. An intriguing issue with parent natural product cephalotaxine (226) is the lability of its enantiomeric purity. Heating its hydrochloric salt or formation of a quaternary ammonium salt have been found to proceed with racemization. As shown in Scheme 41, an iso-Nazarov process was invoked by Liang as well as by other authors to account for this behavior. ${ }^{100}$

Strigolactones are carotenoid-derived plant hormones that play several roles in plant life and thus have triggered considerable research studies (Scheme 42A). ${ }^{101}$ Whereas a lot of knowledge as regards biological intermediates and enzymes involved in their biosynthesis has been gathered, the exact mechanism for their formation remains unclear. The group of Aponick recently reported a biosynthetic proposal based on a cation-initiated cascade that seems to match all the biosynthetic studies performed to date. ${ }^{102}$ As shown in 
Scheme 42B, a 4 $\pi$-electrocyclization process on stabilized cation 232 followed by intramolecular trapping by the carboxylic acid moiety would provide the parent tricyclic core present in these natural cyclopentafuranones. In order to test their hypothesis, the group prepared diastereomeric esters $\mathbf{2 3 4}$ and submitted them to acid treatment. Indeed, trans-olefin (E)-234 underwent cyclization under $\mathrm{TfOH}$ catalysis to deliver lactone 235 almost free from diastereomeric product. A small amount of side-product 236 arising from a non-interrupted cyclization was also isolated. Diastereomeric precursor (Z)-234 required harsher conditions, i. e. prolonged reaction time and stoichiometric acid. In this case, best selectivity was achieved using trimethylsilyl triflate as promoter. Interestingly, no interconversion between products $\mathbf{2 3 8}$ was observed upon acid treatment and the compounds were produced as methyl ethers. It should be noted that the use of a suitable 234 analogue precursor in combination with Liu's gold-catalyzed deoxygenative iso-Nazarov reaction using a silane as external nucleophile (see Scheme 20C) could provide a straightforward entry to strigol's tricyclic core.

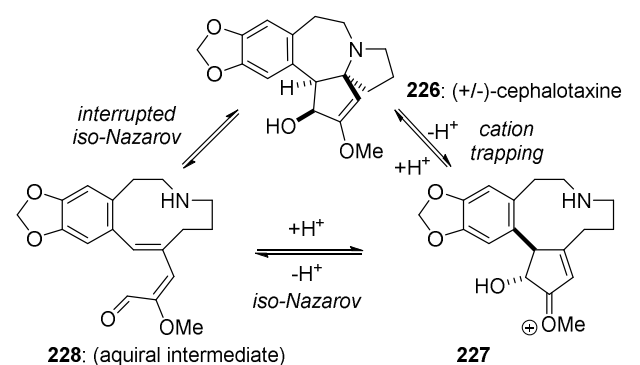

Scheme 41. Iso-Nazarov process proposed to account for the optical lability of cephalotaxine (226).

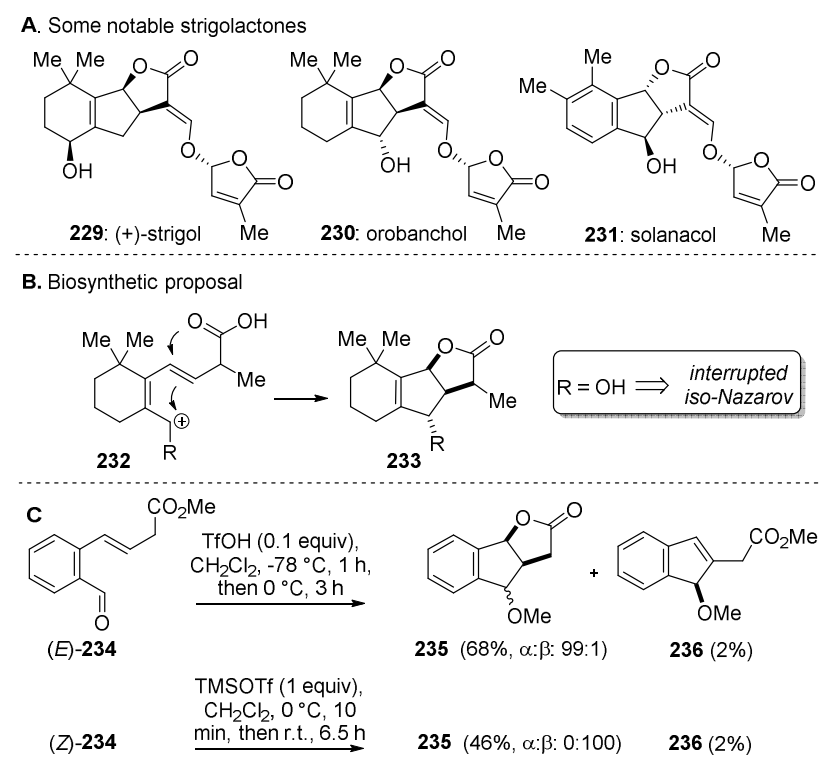

Scheme 42. Interrupted iso-Nazarov reaction for the synthesis of strigolactone analogues.

Reyes and Romo also reported a bioinspired approach featuring an iso-Nazarov reaction (Scheme 43). ${ }^{103}$ En route towards anticancer natural product agelastatin A (242), Brønsted acid treatment of 
intermediate $\mathbf{2 3 7}$ promotes the formation of iminium key species 238 that undergoes conrotatory cyclization towards cyclopentene $\mathbf{2 3 9}$ which is finally trapped by water. Deprotection of the cyclic urea in $\mathbf{2 4 0}$ delivered a flexible intermediate $\mathbf{2 4 1}$ that on silica gel and under mild heating already underwent formation of the last ring. Isomer $\mathbf{2 4 3}$ was also found in the reaction mixture and a hypothesis for its formation was elaborated.
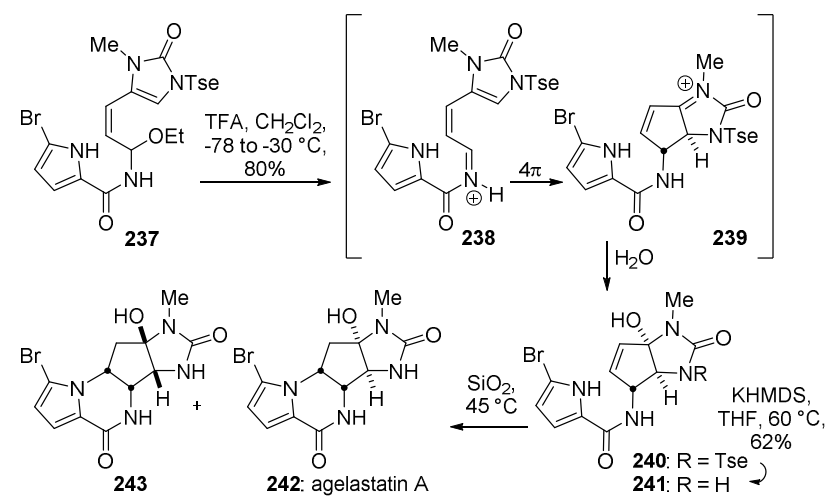

Scheme 43. Bioinspired total synthesis of agelastatin A based on an interrupted imino-iso-Nazarov reaction. Tse $=p$-toluenesulfonylethyl.

\section{Conclusions and Future Perspectives}

The history of the Iso-Nazarov reaction has been presented for the first time. This variant of the remarkable Nazarov cyclization employs linearly-conjugated dienones and dienals to provide valuable 2- and 3-cyclopentenones as well as other five membered-ring systems with ease. Whereas it can still be considered an immature transformation, the number of processes in which it is involved is overwhelming and it has not only been applied to the synthesis of various natural products but also has provided a straightforward access to densely decorated polycyclic frameworks when involved in domino cascades. We expect future studies on this process will result in novel applications and simple enantioselective protocols will emerge that will drive the reaction through the path of fame.

\section{Conflicts of interest}

There are no conflicts to declare.

\section{Acknowledgements}

We thank Consejo Nacional de Investigaciones Científicas y Técnicas (CONICET, PIP 2012-2014 0448), Agencia Nacional de Promoción Científica y Tecnológica (ANPCyT, BID-PICT-0408), Fundación Prats, and Universidad Nacional de Rosario from Argentina for financial support.

Keywords: cycloisomerization reactions $\bullet$ cyclopentenones $\bullet$ dienals $\bullet$ Nazarov $\bullet$ pentadienyl cation 


\section{Notes and references}

[1] For reviews on transition-metal-catalyzed and/or electrophile-promoted cycloisomerizations, see: (a) Y. Yamamoto, Chem. Rev., 2012, 112, 4736-4769; (b) C. Aubert, L. Fensterbank, P. Garcia, M. Malacria and A. Simonneau, Chem. Rev., 2011, 111, 1954-1993; (c) A. Fürstner, Chem. Soc. Rev., 2009, 38, 3208-3221; (d) R. A. Yoder and J. N. Johnston, Chem. Rev., 2005, 105, 4730-4756; (e) A. Eschenmoser and D. Arigoni, Helv. Chim. Acta, 2005, 88, 3011-3050; (f) I. Ojima, M. Tzamarioudaki, Z. Li and R. J. Donovan, Chem. Rev., 1996, 96, 635-662. For a recent review on catalytic enantioselective cycloisomerizations, see: (g) I. D. G. Watson and F. D. Toste, Chem. Sci., 2012, 3, 2899-2919.

[2] For reviews on synthetic methodology for cyclopentenone construction, see: (a) S. P. Simeonov, J. P. M. Nunes, K. Guerra, V. B. Kurteva and C. A. M. Afonso, Chem. Rev., 2016, 116, 5744-5893; (b) D. J. Aitken, H. Eijsberg, A. Frongia, J. Ollivier and P. P. Piras, Synthesis, 2014, 46, 1-24.

[3] For reviews on the Nazarov reaction, see: (a) D. R. Wenz and J. R. de Alaniz, Eur. J. Org. Chem., 2015, 23-37; (b) F. G. West, O. Scadeng, Y.-K. Wu, R. J. Fradette and S. Joy, In Comprehensive Organic Synthesis, ed. G. A. Molander and P. Knochel, Elsevier, Oxford, 2nd ed., 2014, Vol. 5, pp. 827-866; (c) T. Vaidya, R. Eisenberg and A. J. Frontier, ChemCatChem, 2011, 3, 1531-1548; (d) M. A. Tius, Eur. J. Org. Chem., 2005, 2193-2206; (e) A. J. Frontier and C. Collison, Tetrahedron, 2005, 61, 7577-7606; (f) H. Pellissier, Tetrahedron, 2005, 61, 6479-6517; (g) K. L. Habermas, S. E. Denmark and T. K. Jones, In Organic Reactions, ed. L. A. Paquette, John Wiley \& Sons Inc., New York, 1994, Vol. 45, pp. 1-158.

[4] For some selected examples on the use of cyclopentenones as synthetic intermediates, see: (a) J. Chang, X. Song, W. Huang, D. Zhu and M. Wang, Chem. Commun., 2015, 51, 15362-15365; (b) L. Jørgensen, S. J. McKerrall, C. A. Kuttruff, F. Ungeheuer, J. Felding and P. S. Baran, Science, 2013, 341, 878-882; (c) N. K. Reddy, B. V. D. Vijaykumar and S. Chandrasekhar, Org. Lett., 2012, 14, 299-301; (d) K. Fujioka, H. Yokoe, M. Yoshida and K. Shishido, Org. Lett., 2012, 14, 244-247; (e) A. G. Ross, X. Li and S. J. Danishefsky, J. Am. Chem. Soc., 2012, 134, 16080-16084; (f) L. A. Paquette and K. E. Stevens, Can. J. Chem., 1984, 62, 2415-2420.

[5] (a) S. Kawamura, H. Chu, J. Felding and P. S. Baran, Nature, 2016, 532, 90-93; (b) A. Rossi, P. Kapahi, G. Natoli, T. Takahashi, Y. Chen, M. Karin and M. G. Santoro, Nature, 2000, 403, 103-108; (c) G. Büchi, D. M. Foulkes, M. Kurono, G. F. Mitchell and R. S. Schneider, J. Am. Chem. Soc., 1967, 89, 6745-6753; (d) G. Büchi and H. Wüest, J. Org. Chem., 1966, 31, 977-978. See also ref. 2a.

[6] (a) P. Magnus, W. A. Freund, E. J. Moorhead and T. Rainey, J. Am. Chem. Soc., 2012, 134, 6140-6142; (b) K. Yaji and M. Shindo, Tetrahedron, 2010, 66, 9808-9813; (c) G. O. Berger and M. A. Tius, J. Org. Chem., 2007, 72, 6473-6480; (d) W. He, J. Huang, X. Sun and A. J. Frontier, J. Am. Chem. Soc., 2007, 129, 498-499; (e) G. Liang, Y. Xu, I. B. Seiple and D. Trauner, J. Am. Chem. Soc., 2006, 128, $11022-$ 11023.

[7] For a review, see: (a) N. Shimada, C. Stewart and M. A. Tius, Tetrahedron, 2011, 67, 5851-5870. For some selected recent examples, see: (b) Z. Xu, H. Ren, L. Wang and Y. Tang, Org. Chem. Front., 2015, 2, 811-814; (c) K. Kitamura, N. Shimada, C. Stewart, A. C. Atesin, T. A. Ateşin and M. A. Tius, Angew. Chem. Int. Ed., 2015, 54, 6288-6291; (d) G. E. Hutson, Y. E. Türkmen and V. H. Rawal, J. Am. Chem. Soc., 2013, 135, 4988-4991. 
[8] For a review, see: (a) T. N. Grant, C. J. Rieder and F. G. West, Chem. Commun., 2009, 5676-5688. For some recent publications, see: (b) R. William, S. Wang, A. Mallick and X.-W. Liu, Org. Lett., 2016, 18, 4458-4461; (c) D. J. Schatz, Y. Kwon, T. W. Scully and F. G. West, J. Org. Chem., 2016, 81, 1249412498; (d) Y. Kwon, R. McDonald and F. G. West, Angew. Chem. Int. Ed., 2013, 52, 8616-8619.

[9] For some reviews, see: (a) N. S. Sheikh, Org. Biomol. Chem., 2015, 13, 10774-10796; (b) M. J. Di Grandi, Org. Biomol. Chem., 2014, 12, 5331-5345; (c) M. A. Tius, Chem. Soc. Rev., 2014, 43, $2979-$ 3002; (d) W. T. Spencer III, T. Vaidya and A. J. Frontier, Eur. J. Org. Chem., 2013, 3621-3633.

[10] S. E. Denmark and G. A. Hite, Helv. Chim. Acta, 1988, 71, 195-208.

[11] A. K. Miller, M. R. Banghart, C. M. Beaudry, J. M. Suh and D. Trauner, Tetrahedron, 2003, 59, 89198930.

[12] These reactions involve the generation of an acyl radical intermediate from a suitable precursor such as a selenyl ester. For example, see: (a) B. De Boeck, N. M. A. Herbert, N. M. Harrington-Frost and G. Pattenden, Org. Biomol. Chem., 2005, 3, 328-339; (b) N. M. Harrington-Frost and G. Pattenden, Synlett, 1999, 1917-1918.

[13] (a) J. Yang, A. Rérat, Y. J. Lim, C. Gosmini and N. Yoshikai, Angew. Chem. Int. Ed., 2017, 56, 24492453; (b) J. Yang and N. Yoshikai, J. Am. Chem. Soc., 2014, 136, 16748-16751; (c) K. Kundu, J. V. McCullagh and A. T. Morehead, Jr., J. Am. Chem. Soc., 2005, 127, 16042-16043; (d) R. C. Larock, K. Oertle and G. F. Potter, J. Am. Chem. Soc., 1980, 102, 190-197.

[14] (a) M. J. Riveira and M. P. Mischne, Synth. Commun., 2013, 43, 208-220; (b) S. Mandal, K. N. Parida, S. Samanta and J. N. Moorthy, J. Org. Chem., 2011, 76, 7406-7414; (c) J. Buback, M. Kullmann, F. Langhojer, P. Nuernberger, R. Schmidt, F. Würthner and T. Brixner, J. Am. Chem. Soc., 2010, 132, 16510-16519; (d) C.-N. Huang, P.-Y. Kuo, C.-H. Lin and D.-Y. Yang, Tetrahedron, 2007, 63, 1002510033; (e) Z. A. Krasnaya, Chem. Heterocycl. Compd., 1999, 35, 1255-1271.

[15] M. Shoji, J. Yamaguchi, H. Kakeya, H. Osada and Y. Hayashi, Angew. Chem. Int. Ed., 2002, 41, 31923194.

[16] (a) O. Nieto Faza, C. Silva López, R. Álvarez and Á. R. de Lera, Chem.-Eur. J., 2004, 10, 4324-4333. For an excellent review on theoretical studies on pentadienyl cation electrocyclizations also see: (b) R. L. Davis and D. J. Tantillo, Curr. Org. Chem., 2010, 14, 1561-1577.

[17] G. Märkl, A. Roedig and V. Schaal, Chem. Ber., 1962, 95, 2852-2860.

[18] A. Roedig, P. Geist, H. Göpfert and H. Jarosch, Chem. Ber., 1979, 112, 2730-2740.

[19] H. Ogawa, Y. Taketugu, T. Imoto, Y. Taniguchi and H. Kato, Tetrahedron Lett., 1979, 20, 3457-3460.

[20] B. A. Patel, J.-I. I. Kim, D. D. Bender, L.-C. Kao and R. F. Heck, J. Org. Chem., 1981, 46, 1061-1067.

[21] (a) T. K. Jones and S. E. Denmark, Helv. Chim. Acta, 1983, 66, 2397-2411; (b) T. K. Jones and S. E. Denmark, Helv. Chim. Acta, 1983, 66, 2377-2396; (c) S. E. Denmark and T. K. Jones, J. Am. Chem. Soc., 1982, 104, 2642-2645.

[22] M. R. Peel and C. R. Johnson, Tetrahedron Lett., 1986, 27, 5947-5950.

[23] G. R. Elia, R. F. Childs and G. S. Shaw, Can. J. Chem., 1992, 70, 2065-2069.

[24] C. Kuroda and H. Koshio, Chem. Lett., 2000, 962-963.

[25] M. Yoshimatsu, Y. Matsuura and K. Gotoh, Chem. Pharm. Bull., 2003, 51, 1405-1412.

[26] C. Kuroda, S. Honda, Y. Nagura, H. Koshio, T. Shibue and T. Takeshita, Tetrahedron, 2004, 60, $319-331$.

[27] M. J. Porter, N. J. White, G. E. Howells and D. D. P. Laffan, Tetrahedron Lett., 2004, 45, 6541-6543.

[28] C.-Y. Lo, C.-C. Lin, H.-M. Cheng and R.-S. Liu, Org. Lett., 2006, 8, 3153-3156. 
[29] A. P. Marcus, A. S. Lee, R. L. Davis, D. J. Tantillo and R. Sarpong, Angew. Chem. Int. Ed., 2008, 47, 6379-6383.

[30] A. R. Jagdale and S. W. Youn, Eur. J. Org. Chem., 2011, 3904-3910.

[31] W.-M. Liu, Y. L. Tnay, K. P. Gan, Z.-H. Liu, W. H. Tyan and K. Narasaka, Helv. Chim. Acta, 2012, 95, 1953-1969.

[32] C. Kuroda, N. Mitsumata and C. Y. Tang, Bull. Chem. Soc. Jpn., 1996, 69, 1409-1416.

[33] (a) L. F. Tietze, "Domino Reactions: Concepts for Efficient Organic Synthesis", Wiley-VCH, Weinheim, Germany, 2014; (b) H. Pellissier, Chem. Rev., 2013, 113, 442-524; (c) A. Padwa and S. K. Bur, Tetrahedron, 2007, 63, 5341-5378; (d) L. F. Tietze; G. Brasche and K. M. Gericke, "Domino Reactions in Organic Synthesis", Wiley-VCH, Weinheim, Germany, 2006; (e) K. C. Nicolaou, D. J. Edmonds and P. G. Bulger, Angew. Chem. Int. Ed., 2006, 45, 7134-7186; (f) L. F. Tietze, Chem. Rev., 1996, 96, 115-136; (g) H. Waldmann in "Organic Synthesis Highlights II", ed. H. Waldmann, VCH, Weinheim, Germany, 1995, pp. 193-202.

[34] K. Bodendorf and R. Mayer, Chem. Ber., 1965, 98, 3565-3570.

[35] (a) X. Fan, H. Lv, Y.-H. Guan, H.-B. Zhu, X.-M. Cui and K. Guo, Chem. Commun., 2014, 50, 4119-4122. See also: (b) S. Wang, Y. Zhu, Y. Wang and P. Lu, Org. Lett., 2009, 11, 2615-2618.

[36] T. Ohwada, N. Yamagata and K. Shudo, J. Am. Chem. Soc., 1991, 113, 1364-1373.

[37] B. G. Pujanauski, B. A. B. Prasad and R. Sarpong, J. Am. Chem. Soc., 2006, 128, 6786-6787.

[38] A. B. González-Pérez, B. Vaz, O. Nieto Faza and Á. R. de Lera, J. Org. Chem., 2012, 77, 8733-8743.

[39] C.-C. Lin, T.-M. Teng, A. Odedra and R.-S. Liu, J. Am. Chem. Soc., 2007, 129, 3798-3799.

[40] C.-C. Lin, T.-M. Teng, C.-C. Tsai, H.-Y. Liao and R.-S. Liu, J. Am. Chem. Soc., 2008, 130, 16417-16423.

[41] The formation of product 95a does not involve deoxygenation. See ref. 40 for a mechanistic rationale.

[42] M. E. Jung and D. Yoo, J. Org. Chem., 2007, 72, 8565-8568.

[43] M.-P. Heck, C. Matt, A. Wagner, L. Toupet and C. Mioskowski, Eur. J. Org. Chem., 2010, 966-971.

[44] The homotrimerization of propionaldehyde at $230{ }^{\circ} \mathrm{C}$ in $\left(\mathrm{NH}_{4}\right)_{2} \mathrm{HPO}_{4}$ solution was previously shown to afford cyclopentenone 108a in 18\% yield. J. I. Grayson and R. Dinkel, Helv. Chim. Acta, 1984, 67, 21002110.

[45] J. L. Brooks, P. A. Caruana and A. J. Frontier, J. Am. Chem. Soc., 2011, 133, 12454-12457.

[46] J. L. Brooks and A. J. Frontier, J. Am. Chem. Soc., 2012, 134, 16551-16553.

[47] J. L. Brooks, Y.-W. Huang and A. J. Frontier, Org. Synth., 2014, 91, 93-105.

[48] S. D. Jacob, J. L. Brooks and A. J. Frontier, J. Org. Chem., 2014, 79, 10296-10302.

[49] Y.-W. Huang and A. J. Frontier, Tetrahedron Lett., 2015, 56, 3523-3526.

[50] Y.-W. Huang and A. J. Frontier, Org. Lett., 2016, 18, 4896-4899.

[51] R. Ramage, G. J. Griffiths, F. E. Shutt and J. N. A. Sweeney, J. Chem. Soc. Perkin Trans. 1, 1984, 15311537.

[52] For an early example on the cyclization of a dienyl oxocarbenium ion derived from a vinylallene acetal, see: Á. R. de Lera, J. G. Rey, D. Hrovat, B. Iglesias and S. López, Tetrahedron Lett., 1997, 38, 74257428.

[53] W.-D. Z. Li, W.-G. Duo and C.-H. Zhuang, Org. Lett., 2011, 13, 3538-3541.

[54] Y. Chen and W.-D. Z. Li, Tetrahedron Lett., 2017, 58, 248-251.

[55] N. Shimada, C. Stewart, W. F. Bow, A. Jolit, K. Wong, Z. Zhou and M. A. Tius, Angew. Chem. Int. Ed., 2012, 51, 5727-5729. 
[56] (a) F. Li, C. Ding, M. Wang, Q. Yao and A. Zhang, J. Org. Chem., 2011, 76, 2820-2827. The work by Zhang's group was then extended to other substrates and also other conditions such as the use of water as solvent: (b) S. Wang, R. William, K. K. G. E. Seah and X.-W. Liu, Green Chem., 2013, 15, 3180-3183.

[57] For a related domino iso-Nazarov transformation of dihydropyrans not involving amines, see: E. Matoušová, A. Růžička, J. Kuneš, J. Králová and M. Pour, Chem. Commun., 2011, 47, 9390-9392.

[58] Conrotatory $4 \pi$-electrocyclizations of 1 -aminopentadienyl cations have been proposed to account for the photoswitching behaviour of a new class of photoswitches. For example, see: (a) M. M. Lerch, S. J. Wezenberg, W. Szymanski and B. L. Feringa, J. Am. Chem. Soc., 2016, 138, 6344-6347. (b) S. Helmy, F. A. Leibfarth, S. Oh, J. E. Poelma, C. J. Hawker and J. Read de Alaniz, J. Am. Chem. Soc., 2014, 136, 8169-8172.

[59] R. William, S. Wang, F. Ding, E. N. Arviana and X.-W Liu, Angew. Chem. Int. Ed., 2014, 53, $10742-$ 10746.

[60] R. William, W. L. Leng, S. Wang and X.-W. Liu, Chem. Sci., 2016, 7, 1100-1103.

[61] A.-S. Marques, V. Coeffard, I. Chataigner, G. Vincent and X. Moreau, Org. Lett., 2016, 18, 5296-5299.

[62] C. J. Rieder, K. J. Winberg and F. G. West, J. Am. Chem. Soc., 2009, 131, 7504-7505.

[63] O. Nieto Faza, C. Silva López, R. Álvarez and Á. R. de Lera, Chem.-Eur. J., 2009, 15, 1944-1956.

[64] A. Valla and M. Giraud, Synthesis, 1992, 690-693.

[65] A. Valla, Z. Andriamialisoa, F. Zentz, V. Prat, A. Laurent and M. Giraud, Synth. Commun., 2001, 31, 279282.

[66] J.-M. Dillenschneider, L. Dufossé, M. Fouillaud, N. Sutthiwong, R. Labia and A. Valla, J. Heterocycl. Chem., 2016, 53, 1017-1021.

[67] J.-M. Dillenschneider, L. Dufossé, M. Fouillaud, N. Sutthiwong, R. Labia and A. Valla, J. Heterocycl. Chem., 2016, 53, 1439-1442.

[68] A. K. Miller and D. Trauner, Angew. Chem. Int. Ed., 2003, 42, 549-552

[69] M. J. Riveira and M. P. Mischne, J. Org. Chem., 2014, 79, 8244-8254.

[70] A. K. Miller, D. H. Byun, C. M. Beaudry and D. Trauner, Proc. Natl. Acad. Sci. U.S.A., 2004, 101, 1201912023.

[71] For an account, see: A. K. Miller and D. Trauner, Synlett, 2006, 2295-2316.

[72] C. Silva López, O. Nieto Faza, R. Álvarez and Á. R. de Lera, J. Org. Chem., 2006, 71, 4497-4501.

[73] M. J. Riveira, C. Gayathri, A. Navarro-Vázquez, N. V. Tsarevsky, R. R. Gil and M. P. Mischne, Org. Biomol. Chem., 2011, 9, 3170-3175.

[74] M. J. Riveira and M. P. Mischne, Chem.-Eur. J., 2012, 18, 2382-2388.

[75] M. J. Riveira, G. N. Quiroga, E. G. Mata, V. Gandon and M. P. Mischne, J. Org. Chem., 2015, 80, 65156519.

[76] T. Fukuda, Y. Yamaguchi, R. Masuma, H. Tomoda and S. Õmura, J. Antibiot., 2005, 58, 309-314.

[77] T. Fukuda, H. Tomoda and S. Õmura, J. Antibiot., 2005, 58, 315-321.

[78] T. Fukuda, K. Shimoyama, T. Nagamitsu and H. Tomoda, J. Antibiot., 2014, 67, 445-450.

[79] A. D. Fotiadou and A. L. Zografos, Org. Lett., 2011, 13, 4592-4595.

[80] M.-H. Lin, Y.-C. Chen, S.-H. Chiu, Y.-F. Chen and T.-H. Chuang, Molecules, 2016, 21, 1713.

[81] G. Piancatelli, A. Scettri and S. Barbadoro, Tetrahedron Lett., 1976, 17, 3555-3558.

[82] (a) G. Piancatelli and A. Scettri, Synthesis, 1977, 116-117. See also: (b) G. Stork, C. Kowalski and G. Garcia, J. Am. Chem. Soc., 1975, 97, 3258-3260. 
[83] For example see: J. P. Henschke, Y. Liu, X. Huang, Y. Chen, D. Meng, L. Xia, X. Wei, A. Xie, D. Li, Q. Huang, T. Sun, J. Wang, X. Gu, X. Huang, L. Wang, J. Xiao and S. Qiu, Org. Process Res. Dev., 2012, 16, 1905-1916, and references cited therein.

[84] (a) C. Piutti and F. Quartieri, Molecules, 2013, 18, 12290-12312. (b) G. Piancatelli, M. D'Auria and F. D’Onofrio, Synthesis, 1994, 867-889. (c) G. Piancatelli, Heterocycles, 1982, 19, 1735-1744.

[85] R. Antonioletti, A. de Mico, G. Piancatelli, A. Scettri and O. Ursini, Gazz. Chim. Ital., 1986, 116, 745-746.

[86] L. C. Dias, S. B. Shimokomaki and R. T. Shiota, J. Braz. Chem. Soc., 2005, 16, 482-489.

[87] A. G. Csákÿ, M. Mba and J. Plumet, Synlett, 2003, 2092-2094.

[88] R. Katsuta, K. Aoki, A. Yajima and T. Nukada, Tetrahedron Lett., 2013, 54, 347-350.

[89] C.-C. Li, C.-H. Wang, B. Liang, X.-H. Zhang, L.-J. Deng, S. Liang, J.-H. Chen, Y.-D. Wu and Z. Yang, J. Org. Chem., 2006, 71, 6892-6897.

[90] B.-L. Yin, Y.-L. Wu and J.-Q. Lai, Eur. J. Org. Chem., 2009, 2695-2699.

[91] L. I. Palmer and J. Read de Alaniz, Org. Lett., 2013, 15, 476-479.

[92] V. R. Denisov, S. E. Shustitskaya and M. G. Karpov, Zh. Org. Khim., 1993, 29, 249-252.

[93] G. K. Veits, D. R. Wenz and J. Read de Alaniz, Angew. Chem. Int. Ed., 2010, 49, 9484-9487.

[94] D. R. Wenz and J. Read de Alaniz, Org. Lett., 2013, 15, 3250-3253.

[95] L. Marin, V. Gandon, E. Schulz and D. Leboeuf, Adv. Synth. Catal., 2017, 359, 1157-1163.

[96] H. Li, R. Tong and J. Sun, Angew. Chem. Int. Ed., 2016, 55, 15125-15128.

[97] Y. Cai, Y. Tang, I. Atodiresei and M. Rueping, Angew. Chem. Int. Ed., 2016, 55, 14126-14130.

[98] For a recent review on asymmetric catalysis by chiral Brønsted acids, see: D. Parmar, E. Sugiono, S. Raja and M. Rueping, Chem. Rev., 2014, 114, 9047-9153.

[99] For an excellent review on biosynthetic and biomimetic electrocyclizations, see: C. M. Beaudry, J. P. Malerich and D. Trauner, Chem. Rev., 2005, 105, 4757-4778.

[100]L. Planas, J. Pérard-Viret and J. Royer, J. Org. Chem., 2004, 69, 3087-3092. See also ref. 53 and references cited therein.

[101]A. Alder, M. Jamil, M. Marzorati, M. Bruno, M. Vermathen, P. Bigler, S. Ghisla, H. Bouwmeester, P. Beyer and S. Al-Babili, Science, 2012, 335, 1348-1351.

[102]K. Chojnacka, S. Santoro, R. Awartani, N. G. J. Richards, F. Himo and A. Aponick, Org. Biomol. Chem., 2011, 9, 5350-5353.

[103]J. C. P. Reyes and D. Romo, Angew. Chem. Int. Ed., 2012, 51, 6870-6873. 